This item was submitted to Loughborough's Research Repository by the author.

Items in Figshare are protected by copyright, with all rights reserved, unless otherwise indicated.

\title{
Mathematical modeling and design of layer crystallization in a concentric annulus with and without recirculation
}

PLEASE CITE THE PUBLISHED VERSION

http://dx.doi.org/10.1002/aic.14049

\section{PUBLISHER}

Wiley (@ 2013 American Institute of Chemical Engineers)

\section{VERSION}

AM (Accepted Manuscript)

\section{PUBLISHER STATEMENT}

This work is made available according to the conditions of the Creative Commons Attribution-NonCommercialNoDerivatives 4.0 International (CC BY-NC-ND 4.0) licence. Full details of this licence are available at: https://creativecommons.org/licenses/by-nc-nd/4.0/

\section{LICENCE}

CC BY-NC-ND 4.0

\section{REPOSITORY RECORD}

Zhou, Lifang, Min Su, Brahim Benyahia, Aniruddh Singh, Paul I. Barton, Bernhardt L. Trout, Allan S. Myerson, and Richard D. Braatz. 2015. "Mathematical Modeling and Design of Layer Crystallization in a Concentric Annulus with and Without Recirculation". figshare. https://hdl.handle.net/2134/17606. 


\section{Mathematical Modeling and Design of Layer Crystallization in a}

\section{Concentric Annulus With and Without Recirculation}

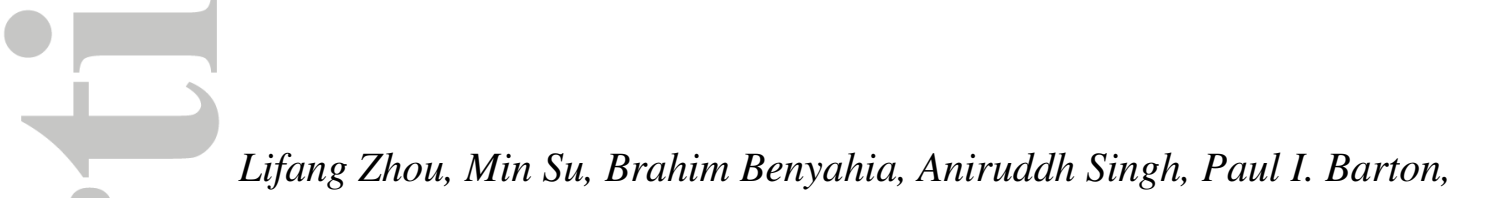

Bernhardt L. Trout, Allan S. Myerson, and Richard D. Braatz*

*Novartis-MIT Center for Continuous Manufacturing and Department of Chemical Engineering,

Massachusetts Institute of Technology, 77 Massachusetts Avenue, Cambridge,

$$
\text { Massachusetts 02139, USA }
$$

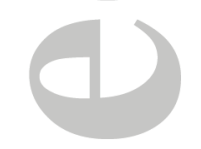

\section{Abstract}

A solution layer crystallization process in a concentric annulus is presented that removes the need for filtration. A dynamic model for layer crystallization with and without a recirculation loop is developed in the form of coupled partial differential equations describing the effects of mass transfer, heat transfer, and crystallization kinetics. The model predicts the variation of the temperature, concentration, and dynamic crystal thickness along the pipe length, and the concentration and temperature along the pipe radius. The model predictions are shown to closely track experimental data that were not used in the model's construction, and also compared to an analytical solution that can be used for quickly obtaining rough estimates when there is no recirculation loop. The model can be used to optimize product yield and crystal layer thickness

This article has been accepted for publication and undergone full peer review but has not been through the copyediting, typesetting, pagination and proofreading process which may lead to differences between this version and the Version of Record. Please cite this article as doi: 10.1002/aic.14049 
uniformity, with constraints on the supersaturation to avoid bulk nucleation by adjusting cooling temperatures in the core and jacket.

Keywords: Solution layer crystallization, crystal growth, distributed parameter systems, process modeling, design

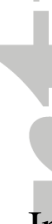

In pharmaceutical manufacturing, drug product is often separated from a liquid phase by crystallization, washing, filtration, and drying_each of which reduce the overall product yield. The crystal habit and size from a crystallization influence the porosity, cake resistance, and compressibility in the filter bed. ${ }^{1}$ Poorly filtering crystals can result in bottlenecks in the downstream processing and can add hours or even days to the process time, which can cause significant mother liquor holdup and affect crystal product purity or reduce yield due to additional washes. These observations have motivated efforts to design continuous crystallization processes that are reliable for manufacturing a product that meets purity, yield, shape, and size requirements, and at the same time ensures efficient downstream processing.

One way to avoid slurry handling is to constrain crystal growth to occur on fixed surfaces so that the amount of solid particles in the bulk is minimized. Layer crystallization has been characterized as being a process in which coherent crystal layers grow on cooled surfaces of a specially designed tube or plate heat exchanger. ${ }^{2,3}$ The crystalline product is removed by melting or dissolving crystals after draining the residual liquid. A primary advantage of layer crystallization is that there are no issues with regard to the addition or removal of solids from the process. Layer crystallization from melts has been widely applied for the purification of organics and inorganics such as sucrose and milk fat, and in seawater desalination. ${ }^{4-7}$ Modeling of solid 
layer melt crystallization has focused on the temperature and composition profiles inside the crystal layer, ${ }^{8-10}$ and multiple stages of crystallizers can be designed to meet the required product purity. ${ }^{11,12}$ For layer crystallization, the liquid phase is always at a higher temperature than the solid phase, so that in melts, the temperature is required to be higher than the melting point, but layer crystallization from solutions can be operated at much lower temperatures. ${ }^{13}$

This paper presents a layer crystallization process from a solution in a concentric annulus that avoids the need for washing, filtration, and drying (see Figure 1). Heterogeneous nucleation occurs on a wire mesh in a seeding stage, and a solid crystal layer forms around the core cylinder in a growth stage. In this way, crystals are kept inside the annulus and only the mother liquor is flowing through the tube or recirculated through a pump. At the end of the crystal growth stage, the mother liquor is completely removed from the annulus, and pure solvent is fed to dissolve the crystal layer. This solution form is especially useful during an intermediate crystallization used to clean up the material before sending to a subsequent liquid-phase chemical reaction. In that case, the produce solvent will be used as a supply to the subsequent reaction. This configuration replaces washing, filtration, and drying with a much simpler and faster process of dissolution. The solvent can be recycled and reused.

Mass transport phenomena in the annulus can have a significant influence on the crystallization. To fully understand and optimize layer crystallization, both diffusive and convective mass transfer rates are needed. Many past studies on mass transfer in annular reactors have concentrated on obtaining correlations of dimensionless numbers for different configurations and operating conditions. ${ }^{14-20}$ Another method is to estimate mass transfer effects of building suitable numerical models that allow the prediction of the concentration fields inside the crystallizer. Melt layer crystallization of $\mathrm{NaCl}-\mathrm{H}_{2} \mathrm{O}$ solution, which can be stationary or 
agitated around the wall of an internally cooled cylindrical tube, has been simulated by Guardani et al. ${ }^{21}$ Duran et al. ${ }^{22}$ carried out computational fluid dynamics (CFD) simulations to predict mass transfer with different hydrodynamic models in annular reactors, with a constant concentration assumed at the solid-liquid surface. These models do not predict the effects of convective heat transfer and solid-layer growth on the concentration distribution in the annulus. Note that heat transfer effects can strongly affect the temperature, which strongly influences the solubility and the supersaturation that drives crystal growth.

Similar to mass transfer, many researchers have investigated correlations for the Nusselt number to characterize convective heat transfer for a wide range of annular diameter ratios and flow conditions, without providing information on the temperature field in the annulus. Commonly, heat transfer in annuli is classified into three categories: (1) uniform heat flux or temperature at the inside wall and adiabatic at the outside surface, ${ }^{23-26}$ (2) uniform heat flux or surface temperature at outside and adiabatic at the inside surface ${ }^{25}$ and (3) constant but different heat fluxes and temperatures at the outside and inside surfaces. ${ }^{27-29}$ In this article, the temperatures of the inside and outside surfaces of the annulus are different from that of the solution, in which case the thermal asymmetry can lead to a discontinuity of the Nusselt number on one surface, depending on the Reynolds number and fluid inlet temperature. ${ }^{28,29}$ Viskanta $^{28}$ provided analytical solutions in terms of series expansions by applying the method of superposition to solve a Sturm-Liouville equation. Two simpler boundary conditions were combined, which included the case of having a constant temperature of one wall combined with the other wall temperature equal to the fluid inlet temperature, but the solutions were not general. Mitrovic et al. ${ }^{29}$ investigated the effect of thermal asymmetry and Reynolds number on the Nusselt number numerically in fully developed laminar flow in an annulus with uniform but 
different inside and outside surface temperatures. Generally, the system is not amenable to the development of simple heat transfer correlations due to the discontinuous Nusselt number that can result from thermal asymmetry in the thermally entrance region. ${ }^{28,29}$ In our case, the initial temperature at inlet and boundary conditions vary over time, and an accurate knowledge of the temperature field is important for predicting the solubility and the supersaturation needed to predict growth rates. This article combines heat transfer and mass transfer models to (1) update the nonuniform boundary temperature at the solid-liquid interface, which is affected by the local thickness of the crystal layer, and (2) calculate the temperature and concentration fields in the annulus.

A cyclic process of layer crystallization would include the initial nucleation of a crystal layer, followed by alternating stages of crystal growth and dissolution. A continuous flow of drug product could be generated by employing multiple cyclic annular crystallizers in parallel. This article focuses on constructing a mathematical model to simulate the layer crystallization process in an annulus with and without a recirculation loop, which is focused on the growth stage as this is the slowest crystal rate process during cyclic operation. Mass and/or heat transfer models with solid-layer growth on a cylindrical surface can be employed for many other applications, such as fouling in heat exchangers, ${ }^{30}$ biofilms in petroleum pipelines, ${ }^{31}$ and melt layer crystallization in a tank ${ }^{8,32}$ However, to our knowledge this is the first article to thoroughly examine heat and mass transfer of a crystallization process with solid-layer growth in an annulus with and without recirculation. The numerical results are compared to first-order analytical solutions that are derived for the layer crystallization without recirculation, and to experimental values to validate the model for a system with recirculation.

\section{Mathematical Model}


Figure 2 shows a scheme of the arrangement for an internally cooled tube surrounded by a liquid solution, surrounded by an external cooled jacket. A cooling fluid is circulated in the inner core to control the temperature of a stainless mesh that supplies nucleation sites and is wrapped on the external wall of the core tube. The outer jacket is circulated with another cooling liquid that is at a higher temperature to suppress bulk nucleation, so a temperature gradient is formed in the middle space between inner core and outer jacket. The supersaturated solution is fed into the middle space between inner core and the jacket, and nuclei form and grow on the cooled stainless steel mesh. The radius of the solid-liquid interface, $r_{s}$, increases at a rate that is controlled by the mass transfer rate in the solution and on the crystal surface.

The growth of the crystal layers moves the position of the solid-liquid interface, in what is known in the literature as a moving boundary problem. The crystal growth rate is much slower than changes in the velocity, concentration, or temperature fields, so quasi-steady thickness of the crystal layer is assumed.

The following assumptions are made for the mass and heat transfer in the system:

(1) Constant solute diffusion coefficient, and constant thermal conductivities and thermal diffusivities of fluid and all solid materials;

(2) Quasi-steady thickness of crystal layer (quasi-steady boundary);

(3) Fully developed laminar flow in the annulus;

(4) Mass and thermal diffusion in the axial direction are negligible;

(5) Natural convection and radiation effects are negligible;

Assumption 3 is justified as the Reynolds number is much less than the transition between laminar and turbulent flow ( $\operatorname{Re}<<1000)$. Assumption 4 is justified because transport due to convection is much larger than transport due to diffusive effects in the axial direction. 
Assumption 5 is justified from the dominance of forced over natural convection and the relatively small range of temperatures.

\section{Mass transfer (liquid phase) model}

Under the above assumptions, as well as Fick's diffusion law, the solute mass balance equation

is

$$
\frac{\partial C}{\partial t}+u(r) \frac{\partial C}{\partial z}=D \frac{1}{r} \frac{\partial}{\partial r}\left(r \frac{\partial C}{\partial r}\right), \quad r_{s} \leq r \leq r_{2 i}, 0 \leq z \leq L
$$

where $C$ is the solute concentration, $D$ is the molecular diffusion coefficient, $z$ is axial distance, $r$ is radial distance, $u(r)$ is the fluid velocity, and $L$ is the total length of the annulus (the subscripts on $r$ are defined in Figure 2). The velocity field for fully developed laminar flow in an annulus is ${ }^{33}$

$$
u(r)=2 \bar{u} \frac{1-\left(\frac{r}{r_{2 i}}\right)^{2}-\frac{1-a^{2}}{\ln a} \ln \left(\frac{r}{r_{2 i}}\right)}{1+a^{2}+\frac{1-a^{2}}{\ln a}}, \quad a=\frac{r_{s}}{r_{2 i}}
$$

where $\bar{u}$ is the average velocity. For layer crystallization in an annulus with recirculation, the solute concentration is dynamically changing, but for a system in quasi-steady state without recirculation under constant feeding, the accumulation rate term $\partial C / \partial t$ in Eq. (1) can be ignored.

For a system with recirculation, the solute concentration at the entrance is the same as that from the exit, and the time delay is not considered due to the small residence time in the recirculation loop. Two limiting conditions are considered: (1) no mixing occurs outside the annulus, so the concentration distribution at the entrance is the same as that from the exit; (2) solute is fully mixed in radial direction through a peristaltic pump, so the entering concentration is uniform and the value is the same as the average concentration from the exit. For a system without recirculation, a solution with constant concentration is fed into the annulus. The crystals 
are assumed to only grow on the outer surface of the core tube, where the mass flux rate is proportional to the growth rate of the crystal layer, so that the solution has the boundary conditions:

$$
\begin{aligned}
& -\left.D \frac{\partial C}{\partial r}\right|_{r=r_{s}}=-k_{i}\left(C_{r_{s}}-C_{s a t}\right)^{n} \\
& -\left.D \frac{\partial C}{\partial r}\right|_{r=r_{2 i}}=0
\end{aligned}
$$

for an annulus with recirculation: $\left\{\begin{array}{l}C(r, z, 0)=C_{0} \\ C(r, 0, t)=C(r, L, t) \text { or } C_{B}(L, t)\end{array}\right.$

for an annulus without recirculation: $C(r, z=0)=C_{0}$

where $k_{i}$ is the integration rate to form crystal, $C_{r_{s}}$ is the concentration at the crystal layer surface, $C_{\text {sat }}$ is solubility, the exponent $n$ is between 1 and $2, C_{0}$ is the initial solute concentration entering the annulus, and $C_{B}$ is the bulk-average concentration at distance $z$, also called the mixing cup concentration that is defined by

$$
C_{B}(z, t)=\frac{\int_{r_{s}}^{r_{2 i}} C(r, z, t) u(r, t) r d r}{\int_{r_{s}}^{r_{2 i}} u(r, t) r d r}
$$

The solute mass flux $j$ and mass transfer coefficient $k_{d}$ at the crystal-solution surface are determined from the definitions

$$
\begin{gathered}
j_{r_{s}}=-\left.D \frac{\partial C}{\partial r}\right|_{r=r_{s}} \\
k_{d}=\frac{j_{r_{s}}}{C_{r_{s}}-C_{B}}
\end{gathered}
$$


where $C_{r_{s}}$ is the concentration at the crystal layer surface and $C_{B}$ is the bulk-average concentration at distance $z$, also called the mixing cup concentration. A combination of Eqns. (5) and (6) results in

$$
k_{d}=-\left.\frac{D}{C_{r_{s}}-C_{B}} \frac{\partial C}{\partial r}\right|_{r=r_{s}}
$$

The mass transfer coefficient $k_{d}$ can be useful in characterizing the relative effects of the mass transfer limitation and the concentration driving force on crystal growth.

\section{Crystal growth (solid phase) model}

The following assumptions are made for crystal growth:

(1) Growth occurs on the crystal surface, with no nucleation and growth in the bulk liquid;

(2) The void fraction in the crystal layer is zero.

The local growth of the crystal layer is derived by the mass balance on the solid:

$$
\frac{d m}{d t}=k_{i}\left(C_{r_{s}}-C_{s a t}\right)^{n} A
$$

where $d m / d t$ is the rate in which solute mass is transported over the area $A=2 \pi r_{s}$. The total crystal mass in a differential element $\Delta z$ in the axial direction can be written as

$$
m=\rho_{s} \pi\left(r_{s}^{2}-r_{m}^{2}\right) \Delta z
$$

where $\rho_{s}$ is the density of the solid phase. The local growth rate can be expressed as

$$
G=\frac{d \delta}{d t}=\frac{d r_{s}}{d t}=\frac{1}{\rho_{s} A} \frac{d m}{d t}
$$

where $\delta=r_{s}-r_{m}$ is the thickness of the crystal layer. Equations (3), (8), and (10) can be combined to give

$$
\frac{d \delta}{d t}=\frac{k_{i}\left(C_{r_{s}}-C_{s a t}\right)^{n}}{\rho_{s}}=\left.\frac{D}{\rho_{s}} \frac{\partial C}{\partial r}\right|_{r_{s}}
$$




\section{Heat transfer model}

The latent heat of crystallization is assumed to be negligible. The assumption is justified as mass transfer is much slower than heat transfer in solution layer crystallization (the thermal diffusivity is much larger than the molecular diffusivity). For example, in the particular application considered in the manuscript, the heat flow associated with the latent heat of crystallization $|q|=\frac{\rho_{s} H_{f u s}}{M} \frac{d \delta}{d t}$ is less than $0.08 \%$ of the heat flow of the solution in the annulus transferring to the inner wall due to cooling $|q|=k_{l} \frac{\partial T}{\partial r}$, where the enthalpy of fusion $H_{f u s}$ is $20.62 \mathrm{~kJ} / \mathrm{mol}$ (this value was obtained by fitting to the van't Hoff equation, $\ln C_{\text {sat }}=-H_{\text {fus }} / R T+$ constant, from solubility data in Ref. 34), the molecular weight of solute Aliskiren hemifumarate $M=0.61 \mathrm{~kg} / \mathrm{mol}$, and $k_{l}$ is the thermal conductivity of the solution.

With the corresponding assumptions as for the mass balances, the energy balance is

$$
\frac{\partial T}{\partial t}+u(r) \frac{\partial T}{\partial z}=\alpha \frac{1}{r} \frac{\partial}{\partial r}\left(r \frac{\partial T}{\partial r}\right), \quad r_{s} \leq r \leq r_{2 i}, \quad 0 \leq z \leq L
$$

where $T$ is the temperature, $\alpha$ is the thermal diffusivity, and $u(r)$ is the fluid velocity. The heat generated during crystallization is assumed to be negligible. Similarly as for the mass balance (1), the accumulation rate term $\partial T / \partial t$ can be neglected for quasi-steady temperature in an annulus without recirculation, and this study considers the two extreme mixing conditions for the system with recirculation. The solution satisfies the boundary conditions: 


$$
\begin{aligned}
& -\left.k_{l} \frac{\partial T}{\partial r}\right|_{r=r_{s}}=U_{1}\left(T_{c 1}-T_{r_{s}}\right) \\
& -\left.k_{l} \frac{\partial T}{\partial r}\right|_{r=r_{2 i}}=U_{2}\left(T_{r_{2 i}}-T_{c 2}\right)
\end{aligned}
$$

for an annulus with recirculation: $\left\{\begin{array}{l}T(r, z, 0)=T_{0} \\ T(r, 0, t)=T(r, L, t) \text { or } T_{B}(L, t)\end{array}\right.$

for an annulus without recirculation: $T(r, z=0)=T_{0}$

where $k_{l}$ is the thermal conductivity of the solution, $T_{c 1}$ and $T_{c 2}$ are the temperatures of the cooling liquid in the core cylinder and outer jacket, $T_{0}$ is the temperature of solution at the inlet, and $U_{1}$ and $U_{2}$ are the overall heat transfer coefficients calculated from

$$
\begin{gathered}
\frac{1}{U_{1} r_{s}}=\left(\frac{1}{h_{c 1} r_{1 i}}+\frac{\ln \left(r_{1 o} / r_{1 i}\right)}{k_{g}}+\frac{\ln \left(r_{m} / r_{1 o}\right)}{k_{m}}+\frac{\ln \left(r_{s} / r_{m}\right)}{k_{s}}\right) \\
\frac{1}{U_{2} r_{2 i}}=\frac{1}{h_{c 2} r_{2 o}}+\frac{\ln \left(r_{2 o} / r_{2 i}\right)}{k_{g}}
\end{gathered}
$$

where $k_{g}, k_{m}$, and $k_{s}$ are the thermal conductivities of the glass, stainless steel mesh, and solid crystal, respectively, and $h_{c 1}$ and $h_{c 2}$ are the heat transfer coefficients of the cooling liquid in the core and the outer jacket, respectively. The derivations of $U_{1}$ and $U_{2}$ are in the Appendix. The local heat flux $q$, heat transfer coefficient $h$, and Nusselt number $\mathrm{Nu}$ for the solution are determined from the definitions

$$
\begin{gathered}
q=-k_{l} \frac{\partial T}{\partial r} \\
h_{1}=-\left.\frac{q}{T-T_{B}}\right|_{r=r_{i i}}, \quad h_{2}=\left.\frac{q}{T-T_{B}}\right|_{r=r_{s}} \\
\mathrm{Nu}=\frac{h d_{e}}{k} \\
d_{e}=d_{2 i}-d_{s}
\end{gathered}
$$


where $d_{e}$ is the equivalent diameter, and $T_{B}$ is the bulk-average fluid temperature, also called the mixing cup temperature. The bulk-average fluid temperature $T_{B}$ is obtained from the temperature profile $T(r, z)$ by

$$
T_{B}(z, t)=\frac{\int_{r_{s}}^{r_{2 i}} T(r, z, t) u(r, t) r d r}{\int_{r_{s}}^{r_{2 i}} u(r, t) r d r}
$$

For the release of heat to the cooling liquids when $T_{c 1}$ and $T_{c 2}$ are less than $T_{B}$ in the annulus, the

Nusselt numbers at the inside and outside walls will be both positive using these definitions. Equations (16), (17), and (18) can be solved to give

$$
N u_{1}=-\left.k \frac{d_{e}}{T_{r_{s}}-T_{B}} \frac{\partial T}{\partial r}\right|_{r=r_{s}} ; \quad N u_{2}=\left.k \frac{d_{e}}{T_{r_{2 i}}-T_{B}} \frac{\partial T}{\partial r}\right|_{r=r_{2 i}}
$$

\section{Analytical and Numerical Methods of Solutions of the Model Equations}

\section{Analytical solution for an annulus without recirculation}

\section{- Solute mass balance}

First-order analytical solutions for the bulk-average concentration $C_{B}$ and crystal layer thickness can be derived with known mass transfer correlations with Sherwood number. The mass flux at axial position $z$ is:

$$
\int_{r_{s}}^{r_{2 i}} C(r, z, t) u(r, t) 2 \pi r d r=\frac{\int_{r_{s}}^{r_{2 i}} C(r, z, t) u(r, t) r d r}{\int_{r_{s}}^{r_{2 i}} u(r, t) r d r} \frac{\int_{r_{s}}^{r_{2 i}} u(r, t) r d r}{\int_{r_{s}}^{r_{2 i}} r d r} \int_{r_{s}}^{r_{2 i}} 2 \pi r d r=C_{B}(z, t) \bar{u}(z, t) A(z, t)
$$

In a control volume of the liquid phase, $\Delta V \approx \pi\left(r_{2 i}^{2}-r_{s}^{2}\right) \Delta z$ marked in a red box in Figure 3 and the solute mass balance is: 
$C_{B}(z, t) \bar{u}(z, t) A(z, t)-C_{B}(z+\Delta z, t) \bar{u}(z+\Delta z, t) A(z+\Delta z, t)-k_{d}\left(\frac{1}{\Delta z} \int_{z}^{z+\Delta z}\left(C_{B}-C \mathrm{l}_{\text {int }}\right) 2 \pi r_{s} d z\right) \Delta z$ $=\frac{d}{d t}\left(\int_{z}^{z+\Delta z} C_{B} A d z\right)$

where $\left.C\right|_{\text {int }}$ is the concentration at the solid-liquid interface and $A \approx \pi\left(r_{2 i}^{2}-r_{s}^{2}\right)$ is the crosssectional area of the liquid phase. Substituting $A$ into Eq. (23), dividing by $\Delta z$ and taking the limit $\Delta z \rightarrow 0$ yields

$$
-\frac{\partial}{\partial z}\left(C_{B} \bar{u}\right) \pi\left(r_{2 i}^{2}-r_{s}^{2}\right)-k_{d}\left(C_{B}-C \mathrm{l}_{\mathrm{int}}\right) 2 \pi r_{s}=\frac{\Delta V}{\Delta z} \frac{\partial C_{B}}{\partial t}=\pi\left(r_{2 i}^{2}-r_{s}^{2}\right) \frac{\partial C_{B}}{\partial t}
$$

Dividing Eq. (24) by $\pi\left(r_{2 i}^{2}-r_{s}^{2}\right)$ and rearranging the terms yields

$$
\frac{\partial C_{B}}{\partial t}+\frac{\partial}{\partial z}\left(C_{B} \bar{u}\right)=-k_{d}\left(C_{B}-\left.C\right|_{\text {int }}\right) \frac{2 r_{s}}{r_{2 i}^{2}-r_{s}^{2}}
$$

The model is simplified by assuming that the thickness $\delta$ of the crystal layer is small compared to $r_{2 i}-r_{m}$, so $r_{s}=r_{m}+\delta \approx r_{m}$. Assuming the velocity $\bar{u}$ is constant along the axial direction $z$ yields

$$
\frac{\partial C_{B}}{\partial t}+\bar{u} \frac{\partial C_{B}}{\partial z}=-k_{d}\left(C_{B}-C \mathrm{I}_{\mathrm{int}}\right) \frac{2 r_{m}}{r_{2 i}^{2}-r_{m}^{2}}
$$

The diffusion layer model (e.g., see Ref. 35) describes crystal growth in terms of two distinct steps: solute diffuses through the boundary layer and is then incorporated into the crystal (Figure 4). The rate of crystal mass can be equated to the diffusion rate through the boundary layer that can be written as

$$
\frac{d m}{d t}=k_{d}\left(C_{B}-C \mathrm{I}_{\text {int }}\right) A .
$$

In the control volume in $\Delta z$,

$$
A=2 \pi r_{s} \Delta z
$$


The rate of solute integration into the crystal surface can be expressed as

$$
\frac{d m}{d t}=k_{i}\left(C \mathrm{I}_{\mathrm{int}}-C_{s a t}\right)^{n} A
$$

If $n=1$, then Eqns. (27) and (29) can be combined to eliminate the interfacial concentration $\left.C\right|_{\text {int }}$ that is difficult to measure, yielding

$$
\frac{d m}{d t}=\left(\frac{1}{k_{d}}+\frac{1}{k_{i}}\right)^{-1}\left(C_{B}-C_{s a t}\right) A
$$

By replacing the consumption term in Eq. (23) with Eq. (30) and repeating the derivation, the solute mass balance can be written as

$$
\frac{\partial C_{B}}{\partial t}+\bar{u} \frac{\partial C_{B}}{\partial z}=-\left(\frac{1}{k_{d}}+\frac{1}{k_{i}}\right)^{-1}\left(C_{B}-C_{s a t}\right) \frac{2 r_{m}}{r_{2 i}^{2}-r_{m}^{2}}
$$

Using a similar derivation, setting $n=2$ in Eq. (29) gives

$$
\begin{aligned}
& \frac{d m}{d t}=\frac{1}{2 k_{i} / k_{d}^{2}}\left(1+\frac{2 k_{i}}{k_{d}} \Delta C-\sqrt{\frac{4 k_{i}}{k_{d}} \Delta C+1}\right) A, \Delta C=C_{B}-C_{s a t} \\
& \frac{\partial C_{B}}{\partial t}+\bar{u} \frac{\partial C_{B}}{\partial z}=-\frac{1}{2 k_{i} / k_{d}^{2}}\left(1+\frac{2 k_{i}}{k_{d}} \Delta C-\sqrt{\frac{4 k_{i}}{k_{d}} \Delta C+1}\right) \frac{2 r_{m}}{r_{2 i}^{2}-r_{m}^{2}}
\end{aligned}
$$

Equation (31) can be simplified by defining the quantity

$$
\begin{gathered}
K:=-\left(\frac{1}{k_{d}}+\frac{1}{k_{i}}\right)^{-1} \frac{2 r_{m}}{r_{2 i}^{2}-r_{m}^{2}} \\
\frac{\partial C_{B}}{\partial t}+\bar{u} \frac{\partial C_{B}}{\partial z}=K\left(C_{B}-C_{s a t}\right)
\end{gathered}
$$

For quasi-steady fluid conditions, the accumulation term is zero but $k_{d}, k_{i}$, and $C_{s a t}$ vary along the axial direction:

$$
\bar{u} \frac{d C_{B}}{d z}=K(z)\left(C_{B}-C_{s a t}(z)\right)
$$


The analytical solution of this first-order ordinary differential equation is

$$
C_{B}(z)=\left(\int_{0}^{z} \frac{-K(\hat{z}) C_{s a t}(\hat{z})}{\bar{u}} \exp \left(\frac{-\int_{0}^{\hat{z}} K(\tilde{z}) d \tilde{z}}{\bar{u}}\right) d \hat{z}+C_{0}\right) \exp \left(\frac{\int_{0}^{z} K(\tilde{z}) d \tilde{z}}{\bar{u}}\right)
$$

\section{- Growth of the crystal layer}

By substituting Eq. (30) into Eq. (10) gives

$$
\frac{d \delta}{d t}=\left(\frac{1}{k_{d}}+\frac{1}{k_{i}}\right)^{-1} \frac{C_{B}-C_{s a t}}{\rho_{s}}
$$

Combining Eq. (37) and (38) gives

$$
\frac{d \delta}{d t}=\left(\frac{1}{k_{d}}+\frac{1}{k_{i}}\right)^{-1} \frac{\left(\int_{0}^{z} \frac{-K(\hat{z}) C_{s a t}(\hat{z})}{\bar{u}} \exp \left(\frac{-\int_{0}^{\hat{z}} K(\tilde{z}) d \tilde{z}}{\bar{u}}\right) d \hat{z}+C_{0}\right) \exp \left(\frac{\int_{0}^{z} K(\tilde{z}) d \tilde{z}}{\bar{u}}\right)-C_{s a t}}{\rho_{s}}
$$

The analytical solution of the thickness is

$$
\delta(t)=\left(\frac{1}{k_{d}}+\frac{1}{k_{i}}\right)^{-1} \frac{\left(\int_{0}^{z} \frac{-K(\hat{z}) C_{s a t}(\hat{z})}{\bar{u}} \exp \left(\frac{-\int_{0}^{\hat{z}} K(\tilde{z}) d \tilde{z}}{\bar{u}}\right) d \hat{z}+C_{0}\right) \exp \left(\frac{\int_{0}^{z} K(\tilde{z}) d \tilde{z}}{\bar{u}}\right)-C_{s a t}}{\rho_{s}} t+\delta_{0}
$$

\section{Numerical solution for an annulus with and without recirculation}

The layer crystallization without recirculation was simulated using the pdepe solver in MATLAB $^{\circledR}$ R2011a by taking 101 mesh points in the axial direction $z$ and 101 mesh points in the radial direction $r$. The method of lines (MOL) was applied for the system with recirculation, that is, the spatial derivatives in the partial differential equations (1) and (12) were first approximating by finite differences. In particular, the first-order derivatives in $z$ are replaced by two-point upwind differences and the derivatives in $r$ were replaced by central differences. Then the ode15s solver in MATLAB ${ }^{\circledR}$ R2011a was employed to numerically solve the resulting timedependent ordinary differential equations. The numerical solutions of the mass balance (1) and 
energy balance (12) were obtained by taking 75 mesh points in each direction. For updating the moving boundary due to growth of the crystal layer, the time period was discretized into 200 grid cells, with finer time steps at the beginning.

A flow sheet for the numerical algorithm is in Figure 5. The lower boundary $r_{s}$ in Eqns. (1) and (12) is time dependent, so the boundary moves as the crystal layer grows thicker. For quasisteady thickness, the solid-liquid interface moves slowly and so can be accurately computed, at each time step, from a first-order temporal discretization of the solute mass balance Eq.(11):

$$
\delta(z, t)=\delta(z, t-\Delta t)+\left.\int_{t}^{t+\Delta t} \frac{D}{\rho_{s}} \frac{\partial C}{\partial r}\right|_{r=r_{s}} d t
$$

Then the temperature and concentration fields are calculated using the new thickness profile along the length of the annulus, and average thickness of the crystal layer is used to update the new velocity profile and new mass and heat transfer boundary conditions.

\section{Experimental System and Parameters}

A jacketed glass column with inner glass core wrapped in a wire mesh (see Figure 6) was applied for the crystallization of Aliskiren hemifumarate (99.7\% purity, provided by Novartis). The length of the annulus is $0.4 \mathrm{~m}$, the inner radius of core glass tube $r_{1 i}$ is $0.0065 \mathrm{~m}$, and the inner radius of hollow jacketed cylinder $r_{2 i}$ is $0.014 \mathrm{~m}$. The thicknesses of the glass layer and stainless steel wire mesh are $2 \mathrm{~mm}$ and $\sim 1 \mathrm{~mm}$, respectively. A dilute solution of Aliskiren hemifumarate (initial concentration of $0.016 \mathrm{~g}$ solute/g total) in ethyl acetate-ethanol mixture with a mass concentration ratio of $95: 5$ at an initial temperature of $60^{\circ} \mathrm{C}$ was used as the fluid between the core and jacket wall. The cooling liquid in core and jacket was a mixture of $70 \%$ ethylene glycol and $30 \%$ water in mass. The cooling temperature in core was $-10^{\circ} \mathrm{C}$, while the temperature in jacket was $20^{\circ} \mathrm{C}$. The core temperature was set lower than the jacket 
temperature in order to avoid bulk nucleation. The flow rate of cooling liquid was $24 \mathrm{~L} / \mathrm{min}$, which is much higher than the flow rate of the solution $(10 \mathrm{~mL} / \mathrm{min})$, so the temperature of the glass wall in contact with the cooling liquid can be regarded as constant along the annulus. ${ }^{1}$ The experiment included two separate steps: seed generation in stationary solution and crystal growth with closed-loop circulation. Supersaturated Aliskiren hemifumarate solution for seed generation was fed into the column and kept stationary for thirty hours to create a crystal layer. The thickness of the crystal layer after seeding was $0.1 \mathrm{~mm}$ as calculated by mass balance from the measured concentration. Then the mother liquor for seeding was drained and the solution for growth was fed. A peristaltic pump was used to produce required driving force for circulation in the crystallizer in growth stage. In experiments, samples of solution were drawn at the outlet of the column, and filtered with $0.22 \mu \mathrm{m}$ syringe filter (Cole Parmer) to determine the concentration with high-performance liquid chromatography (Agilent 1200) and hence the yield.

The diffusion coefficient $D$ for Aliskiren hemifumarate is estimated as $1 \times 10^{-9} \mathrm{~m}^{2} / \mathrm{s}$ using the Wilke-Chang method. ${ }^{36}$ The density of crystal solid is $1200 \mathrm{~kg} / \mathrm{m}^{3}$, and the density of the ethyl acetate-ethanol mixture (95:5 in mass) is $894 \mathrm{~kg} / \mathrm{m}^{3}$. The dynamic viscosity of the solution is $4.52 \times 10^{-2} \mathrm{~Pa} \cdot \mathrm{s}$, and thermal diffusivity of the solution is $7.9 \times 10^{-8} \mathrm{~m}^{2} / \mathrm{s}$. The thermal conductivities of glass $k_{g}$, stainless mesh $k_{m}$, and solution $k_{l}$ are $1.05 \mathrm{~W} / \mathrm{m} \cdot \mathrm{K}, 16 \mathrm{~W} / \mathrm{m} \cdot \mathrm{K}$, and $0.137 \mathrm{~W} / \mathrm{m} \cdot \mathrm{K}$ respectively. Because thermal conductivities of small-molecule organic solid materials are in the range of $0.1273-0.3472 \mathrm{~W} / \mathrm{m} \cdot \mathrm{K},{ }^{37}$ and the crystal is immersed in the solvent, the thermal conductivity of the Aliskiren hemifumarate solid crystal layer is estimated as the same as the ethyl acetate-ethanol mixture, $0.137 \mathrm{~W} / \mathrm{m} \cdot \mathrm{K}$. Since the volumetric flow rate of the

${ }^{1}$ For heat transfer in an annulus without recirculation, the temperature difference between the inlet and outlet core and jacket cooling flows is only $0.0225^{\circ} \mathrm{C}$ and $0.0122^{\circ} \mathrm{C}$, respectively. For heat transfer in an annulus with recirculation, the temperature difference is within $0.0001^{\circ} \mathrm{C}$. 
cooling liquid at $24 \mathrm{~L} / \mathrm{min}$ is very high relative to the solution flow rate, $T_{1 i}$ and $T_{2 o}$ can be assumed equal to $T_{c 1}$ and $T_{c 2}$, respectively.

The solubility of Aliskiren hemifumarate in 95:5 ethyl acetate:ethanol solvent between -10 and $60^{\circ} \mathrm{C}$ was fit to the experimental data in Ref. 34 using a piecewise cubic Hermite interpolating polynomial. The growth rate expression $G(\mathrm{~m} / \mathrm{s})$ fit to experimental data under well-mixed conditions for this system in a past study ${ }^{34}$ is given by

$$
G=\frac{d h}{d t}=4.833 \times 10^{-6} \exp \left(-\frac{2935}{R(T+273)}\right)\left(\frac{\left.C\right|_{\text {int }}-C_{\text {sat }}}{C_{\text {sat }}}\right)^{1.08}
$$

This expression was fit to data collected over the same range of supersaturation as in the solution layer crystallization simulations. For the analytical solution, the mass transfer coefficient $k_{d}$ was calculated first from its correlations with the Sherwood number ${ }^{17-20}$ in Table 1.

The relationship between the average Sherwood number and local Sherwood number is

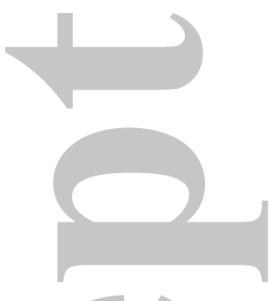

$$
\mathrm{Sh}=\frac{\int_{0}^{L} \mathrm{Sh}_{z} d z}{\int_{0}^{L} d z}
$$

and the diffusion rate coefficient can be calculated from

$$
k_{d}=\frac{\operatorname{Sh}_{z} D}{d_{e}}
$$

\section{Results and Discussion}

\section{Simulation results for an annulus without recirculation}

The quasi-steady Aliskiren hemifumarate concentration field in the annulus without recirculation is shown in Figure 7 . Because the feed temperature $\left(60^{\circ} \mathrm{C}\right)$ is much higher than the 
temperature at the solid-liquid interface, dissolution occurs near the inlet, resulting in a solute concentration peak in Figure 7. As the solution cools while flowing through the annulus, the growth of crystal layer on the core depletes the concentration of solute in the solution.

As it can be seen in the Figure 8, local numerically computed mass transfer coefficients are with the ranges of those calculated from the correlations in Table 1, especially those generated by fits to data by Ross et al. ${ }^{17}$ and Ould-Rouis et al. ${ }^{19}$ The decrease of the local mass transfer coefficients along the axial direction is associated with the reduction of the magnitude of the derivative of the solute concentration with respect to $r$ at the core $\left(r_{s}=0.0096\right)$ as seen in Figure 7.

To investigate heat transfer along the axial direction, Nusselt numbers and the heat flux of the solution for the inside core and outside jacket are plotted in Figure 9 and Figure 10. Infinite $\mathrm{Nu}$ number in Figure 9 is caused by its definition: when $T_{B}$ reaches the outside wall temperature $T_{w}$, the driving temperature difference $T_{w}-T_{B}$ used for the definition of $h$ in Eq. (17) becomes zero, whereas the actual wall heat flux $(\partial T / \partial r)_{r=r_{2 i}}$ is not zero. This observation ${ }^{28,29}$ for such systems with a thermal asymmetry limits the usefulness of evaluating heat flows in terms of plots of the Nusselt number. The heat flux calculated from the numerical solution of temperature is more useful for examining the heat transfer along the axial direction (Figure 10). Because the initial inlet solution temperature is higher than both the cooling temperatures in the core and in the jacket, the heat flows from the solution to the jacket and core in opposite directions first. At the axial position where the solution is cooled to the temperature between the temperatures of the core and jacket, heat flows from outside to inside, so then the heat flux for each side is negative. At the end of the annulus, the heat transfer rate $Q \propto q r$ is the same, which equals to $-9.4 \mathrm{~W} / \mathrm{m}$ for both sides. 
To derive the analytical solution, the exponent $n$ in the integration rate expression (29) was set to 1 , so $n=1$ was used in the numerical method for comparison. Similar to the comparison of mass transfer coefficients, numerical results of the solute concentration and crystal layer thickness versus axial distance in Figure 11 are within the calculated values with mass transfer coefficients from correlations of Ross et al. ${ }^{17}$ and Ould-Rouis et al. ${ }^{19}$ A higher mass transfer coefficient leads to faster depletion of solute concentration, and larger crystal layer thickness. The numerical method has the advantage of providing more insight into the analyzed system by providing the concentration field in the radial direction, which is information that is not provided by the analytical solution derived from mass transfer correlations. In addition, the numerical solution can be solved when $n \neq 1$, which is not true for the analytical solution.

\section{Simulation results for an annulus with recirculation}

The solute concentration field at time $t=3 \mathrm{~min}$ in the annulus with recirculation is shown in Figure 12 and the dynamic radial concentration profile at the exit in Figure 13. For these simulation results for layer crystallization with recirculation, the solution in the recirculation loop is uniformly mixed unless otherwise stated. Concentration gradients are initially large, with the solute concentration near the core much lower than at the outer jacket wall (see Figure 13). These observations indicate that fluid-phase mass transfer resistance dominates under these conditions. The integration rate of crystal growth has less effect on the bulk-average concentration profile, since the primary mass transfer resistance in the fluid is diffusional.

The temperature field at time $\mathrm{t}=3 \mathrm{~min}$ in the annulus is shown in Figure 14 , and dynamic radial temperature profiles at the exit in Figure 15. The radial exit temperature reaches a quasisteady linear profile between the core and jacket within 3 min (see Figure 15). The time scale for heat conduction is $\tau_{\text {conduction }} \approx d_{e}^{2} / \alpha=5.2 \times 10^{2} \mathrm{~s}$ where $d_{e}=d_{2 i}-d_{s}$ for the solution in an annulus, 
and the diffusion time scale is $\tau_{\text {diffusion }} \approx d_{e}^{2} / D=4.1 \times 10^{4} \mathrm{~s}$. Comparison between the temperature and concentration profiles agrees with the time-scale analysis that heat transfer is much faster than mass transfer in this system, and reaches quasi-steady conditions much more quickly. In Figure 15, the solution temperature near the core and near the exit is higher than the temperature of cooling liquid $-10^{\circ} \mathrm{C}$, and the solution temperature near the jacket is lower than $20^{\circ} \mathrm{C}$, due to the thermal resistance of the crystal layer, glass, and convection of the cooling liquids.

The shape of the solubility field in Figure 16 has qualitatively similarities to the temperature field in Figure 14 since the solubility is higher where the temperature is higher. Because the reported solubility curve of Aliskiren hemifumarate is highly nonlinear ${ }^{34}$, this nonlinearity is reflected on the solubility field in the radial direction in Figure 17. For fixed values of the axial position, an intermediate peak in the supersaturation is observed (see Figure 17), which results from different gradients of the reduction of solute concentration due to the integration of solute at the solid-liquid surface close to the core cylinder in Figure 12 and the increase in solubility close to the jacket with higher temperature in Figure 16.

\section{Model Validation}

To evaluate the predictive capability of the model, simulated dynamic bulk-average exit solute concentrations with different assumed mixing conditions for the recirculation loop are compared to experimental values in Figure 18, where all of the parameters in the simulations were taken from the references, with no parameters fitted to the experimental concentrations in this study. The solute concentration initially decreases faster due to a higher driving force for diffusion and integration. Increased mixing in the recirculation loop increases the reduction in the solute concentration and results in a shorter time in depletion of the solute in solution. The experimental values in the first 10 hours are between the simulated concentrations for the two extreme mixing 
limits, suggesting that the mixing in the recirculation loop in reality is between uniform radial mixing and non-mixing, which is consistent with expectation from the experimental setup. After 10 hours, the exit solute concentration has dropped from its initially high value to almost reach solubility for the quasi-steady temperature, with the remaining low supersaturation resulting in very slow growth of crystal layer and slow depletion of solute concentration.

The two sets of simulations and experiments as presented in Figure 18 have different initial solute concentrations ( 0.016 and $0.020 \mathrm{~g}$ solute/g total) and different temperature values for the cooling liquid in the jacket $\left(20^{\circ} \mathrm{C}\right.$ and $\left.30^{\circ} \mathrm{C}\right)$, with Set 2 having a higher final concentration than Set 1 . The exit solute concentration is very weak function of the jacket cooling temperature, because its value is mostly specified by the solubility on the crystal surface at the end of the core tube, which depends on the local temperature. The somewhat higher exit concentration of Set 2 is associated with the higher temperature of the surface of the crystal layer at the exit, which is mainly due to having a larger thermal resistance from a thicker crystal layer resulting from the higher initial concentration. $^{2}$

As it can be seen in Figure 18, the predicted concentration agrees with the experiments, however, the model to some extent overestimates the yield at the end of the two sets of experiments. Possible reasons are: (1) the solubility used in the model is lower than the experimental solubility; (2) the calculated thermal resistance is smaller than the experimental thermal resistance due to uncertainty in the thermal conductivity of the crystal layer, or (3) solvent inclusions in the crystal layer result in a thicker crystal layer with higher thermal resistance, thus higher surface temperature on the crystal surface.

${ }^{2}$ A prerequisite for this and other conclusions is that the solute concentration in the whole annulus is below the metastable limit; which was true for these experimental conditions as no crystal solids were observed other than at the crystal layer. 


\section{Model predictions for different operating conditions}

To study the influence of the temperature $T_{c 1}$ of the cooling liquid in the hollow core cylinder, its value was varied between $-10^{\circ} \mathrm{C}$ and $5^{\circ} \mathrm{C}$. Figure 19 shows the model predictions for the crystal yield in the annulus with recirculation. The yield is improved by decreasing the core cooling liquid temperature, but the effect is not linear. The lowest values of the temperature at the surface of the crystal layer are $-6.77,-2.31,2.15$, and $6.61^{\circ} \mathrm{C}$ for the $T_{c 1}$ of $-10,-5,0$, and $5^{\circ} \mathrm{C}$, respectively, with the differences between the two temperatures due to the thermal resistance of glass, wire mesh, and crystal layers with different values of thickness. The nonlinearity of the yield is mostly due to the nonlinearity in the solubility curve $\mathrm{C}^{34}$ from $-6.77^{\circ} \mathrm{C}$ to $6.61^{\circ} \mathrm{C}$.

Figure 20 shows that higher solution flow rate results in a faster increase of yield if there is mixing in the recirculation loop, but does not significantly affect the yield for this range of flow rates when no mixing occurs in the recirculation loop. When there is mixing in the recirculation loop, higher solution flow rate increases the circulation times by reducing the residence time in each pass of the flow in the annulus, thus accelerating mass transfer in the annulus, and causing a faster increase of the crystal yield.

Figure 21 shows the temporal variation in the crystal layer thickness along the annulus direction with and without mixing in the recirculation loop. As expected, the growth rate of the crystal layer is initially relatively fast, and monotonically decreasing with time. No visible difference can be observed from the spatially averaged crystal layer thickness at 10 hours and 30 hours, which is consistent with the dynamic profiles of the solution concentration versus axial position (Figure 18). The crystal layer thickness is much more spatially uniform when there is no mixing in the recirculation loop (compare Figures 21a and 21b). For uniform mixing in the 
recirculation loop, the crystal layer becomes much thicker close to the inlet than at other positions, which is associated with higher supersaturation near the crystal layer near the inlet of the annulus. The non-monotonic thickness of the crystal layer is similar to the variation of growth rate on a flat crystal face and dendritic crystals in melt crystallization where higher supercooling leads to faster growth as heat transfer dominates. ${ }^{38,39}$ Spatial nonuniformity of the crystal layer thickness increased and then decreased over time (see Figure 21b), the thickness near the inlet decreased between 10 and 30 hours. At those times the uniform temperature at the inlet becomes higher than the boundary temperature on the solid surface and the solute concentration becomes lower than its solubility, so that the crystal layer close to the inlet being to dissolve. The dissolved solute increased the solute concentration, so the crystal layer continued to grow at the downstream positions.

\section{Conclusions}

A numerical study of the layer crystallization process in an annulus with and without recirculation was carried out to predict the solute concentration and temperature fields and the crystal layer thickness along the axial position as a function of time. The mathematical model includes the mechanisms of heat and mass transfer, with mass transfer resistance dominating in this solution system, which is different from melt layer crystallization. Experiments were conducted to evaluate the predictive capability of the mathematical model, where none of the experiments were used in the determination of any model parameters. The mathematical model accurately predicted the measured solute concentrations over time (see Figure 18).

The effects of modifying the operating conditions was investigated, including variation in initial solute concentrations, cooling liquid jacket temperature, inlet solution velocities, core liquid temperature, and extent of mixing in the recirculation loop. The latter extent of mixing 
was shown to have significant effects on spatial uniformity of the crystal layer. An interesting observation was that, for some operating conditions, the extent of spatial nonuniformity of the crystal layer thickness can vary nonmonotonically over time.

The mathematical model can be used to further optimize the process operations. Generally solute-solvent combinations that have high crystal growth rate and relatively low primary nucleation rates and crystallizer designs with the most surface area for crystal growth will have the highest productivity in a layer crystallization. A lower cooling temperature in the core tube leads to a higher product yield, and the model can be used to predict the values of the cooling temperature that ensure that the supersaturation everywhere in the annulus is lower than the metastable limit so as to satisfy the operational constraint of having no bulk nucleation. When the flow in the recirculation loop is uniformly mixed, a higher solution flow rate resulted in a faster increase of crystal yield due to enhanced mass transfer (but does not affect the yield at long time), and the model can be used to determine how high of a flow rate would be needed for the spatially-averaged crystal mass growth rate to be near (e.g., within 90\%) its maximum. Having no mixing in the recirculation loop grows a crystal layer of more spatially uniform thickness, but with lower spatially-averaged crystal growth rate, than when mixing occurs in the recirculation loop. The determination of the optimal spatial or temporal variation of the jacket and core liquid cooling temperature could be investigated as a way to make the supersaturation more uniform at the crystal layer surface over space and time, which would tend to improve molecular purity. Alternatively, the model could be extended to predict molecular purity of the crystal layer, by considering more components, in which case the operating conditions could be optimized to maximize overall process productivity while satisfying a constraint on the molecular purity. 


\section{Appendix}

For the temperature inside and near the core tube, a heat transfer equation can be written for each of the four regions (core tube interior, core tube glass wall, crystal layer, and solution at solid-liquid interface) as shown in the left red box in Figure 2. The steady-state heat conduction equations for the glass wall, stainless steel mesh, and crystal layer are given by ${ }^{40}$

$$
\begin{aligned}
& Q=Q_{g}=\frac{k_{g} 2 \pi L}{\ln \left(r_{1 o} / r_{1 i}\right)}\left(T_{1 i}-T_{1 o}\right) \\
& Q=Q_{m}=\frac{k_{m} 2 \pi L}{\ln \left(r_{m} / r_{1 o}\right)}\left(T_{1 o}-T_{m}\right) \\
& Q=Q_{s}=\frac{k_{s} 2 \pi L}{\ln \left(r_{s} / r_{m}\right)}\left(T_{m}-T_{s}\right)
\end{aligned}
$$

The convection equations for heat transfer at the core tube interior and solid-liquid interface are

$$
\begin{gathered}
Q=Q_{c 1}=h_{c 1} 2 \pi r_{1 i} L\left(T_{c 1}-T_{1 i}\right) ; \\
Q=Q_{1}=q A=-\left.k_{l} 2 \pi r_{s} L \frac{\partial T}{\partial r}\right|_{r=r_{s}} .
\end{gathered}
$$

Eliminating the temperatures in Eqns. (45) to (48) and solving for $Q$ yields

$$
Q\left(\frac{1}{h_{c 1} 2 \pi r_{1 i} L}+\frac{\ln \left(r_{1 o} / r_{1 i}\right)}{k_{g} 2 \pi L}+\frac{\ln \left(r_{m} / r_{1 o}\right)}{k_{m} 2 \pi L}+\frac{\ln \left(r_{s} / r_{m}\right)}{k_{s} 2 \pi L}\right)=T_{c 1}-T_{s}
$$

Eliminating the $Q$ in Eqns. (49) and (50) yields

$$
-\left.k_{l} 2 \pi r_{s} L \frac{d T}{d r}\right|_{r=r_{s}}=\frac{1}{\frac{1}{h_{c 1} 2 \pi r_{1 i} L}+\frac{\ln \left(r_{1 o} / r_{1 i}\right)}{k_{g} 2 \pi L}+\frac{\ln \left(r_{m} / r_{1 o}\right)}{k_{m} 2 \pi L}+\frac{\ln \left(r_{s} / r_{m}\right)}{k_{s} 2 \pi L}}\left(T_{c 1}-T_{s}\right) .
$$

The heat flux is

$$
q=-\left.k_{l} \frac{d T}{d r}\right|_{r=r_{s}}=\frac{1}{\left(\frac{1}{h_{c 1} 2 \pi r_{1 i} L}+\frac{\ln \left(r_{1 o} / r_{1 i}\right)}{k_{g} 2 \pi L}+\frac{\ln \left(r_{m} / r_{1 o}\right)}{k_{m} 2 \pi L}+\frac{\ln \left(r_{s} / r_{m}\right)}{k_{s} 2 \pi L}\right) 2 \pi r_{s} L}\left(T_{s}-T_{c 1}\right)
$$


Thus,

$$
\begin{aligned}
& -\left.k_{l} \frac{\partial T}{\partial r}\right|_{r=r_{s}}=U_{1}\left(T_{c 1}-T_{s}\right) \\
& \frac{1}{U_{1} r_{s}}=\left(\frac{1}{h_{c 1} r_{1 i}}+\frac{\ln \left(r_{1 o} / r_{1 i}\right)}{k_{g}}+\frac{\ln \left(r_{m} / r_{1 o}\right)}{k_{m}}+\frac{\ln \left(r_{s} / r_{m}\right)}{k_{s}}\right)
\end{aligned}
$$

The derivation of $U_{2}$ is similar.

\section{Acknowledgement}

We greatly acknowledge Novartis for the support of this research.

\section{Notation}

$a \quad$ annulus ratio, $r_{s} / r_{2 i}$ (dimensionless)

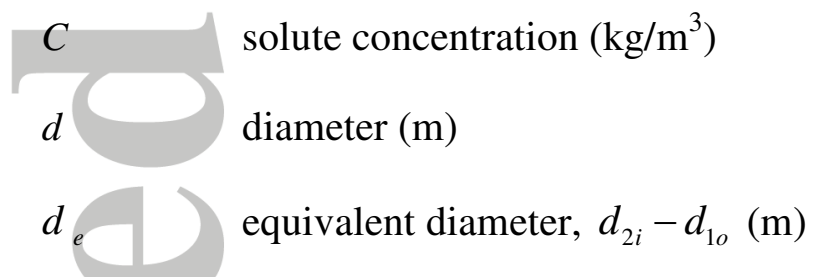

$D \quad$ molecular diffusion coefficient $\left(\mathrm{m}^{2} / \mathrm{s}\right)$

$h \quad$ heat transfer coefficient $\left(\mathrm{W} / \mathrm{m}^{2} \cdot \mathrm{K}\right)$

$H_{\text {fus }}$ enthalpy of fusion $(\mathrm{kJ} / \mathrm{mol})$

$j \quad \operatorname{mass}$ flux $\left(\mathrm{kg} / \mathrm{m}^{2} \mathrm{~s}\right)$

$k_{d} \quad$ mass transfer coefficient $(\mathrm{m} / \mathrm{s})$

$k_{i}$ integration growth rate $(\mathrm{m} / \mathrm{s})$

$k$ thermal conductivity $(\mathrm{W} / \mathrm{m} \cdot \mathrm{K})$

$k_{g} \quad$ thermal conductivity of glass $(\mathrm{W} / \mathrm{m} \cdot \mathrm{K})$

thermal conductivity of solid crystal $(\mathrm{W} / \mathrm{m} \cdot \mathrm{K})$

$q$

heat flux $\left(\mathrm{W} / \mathrm{m}^{2}\right)$ 


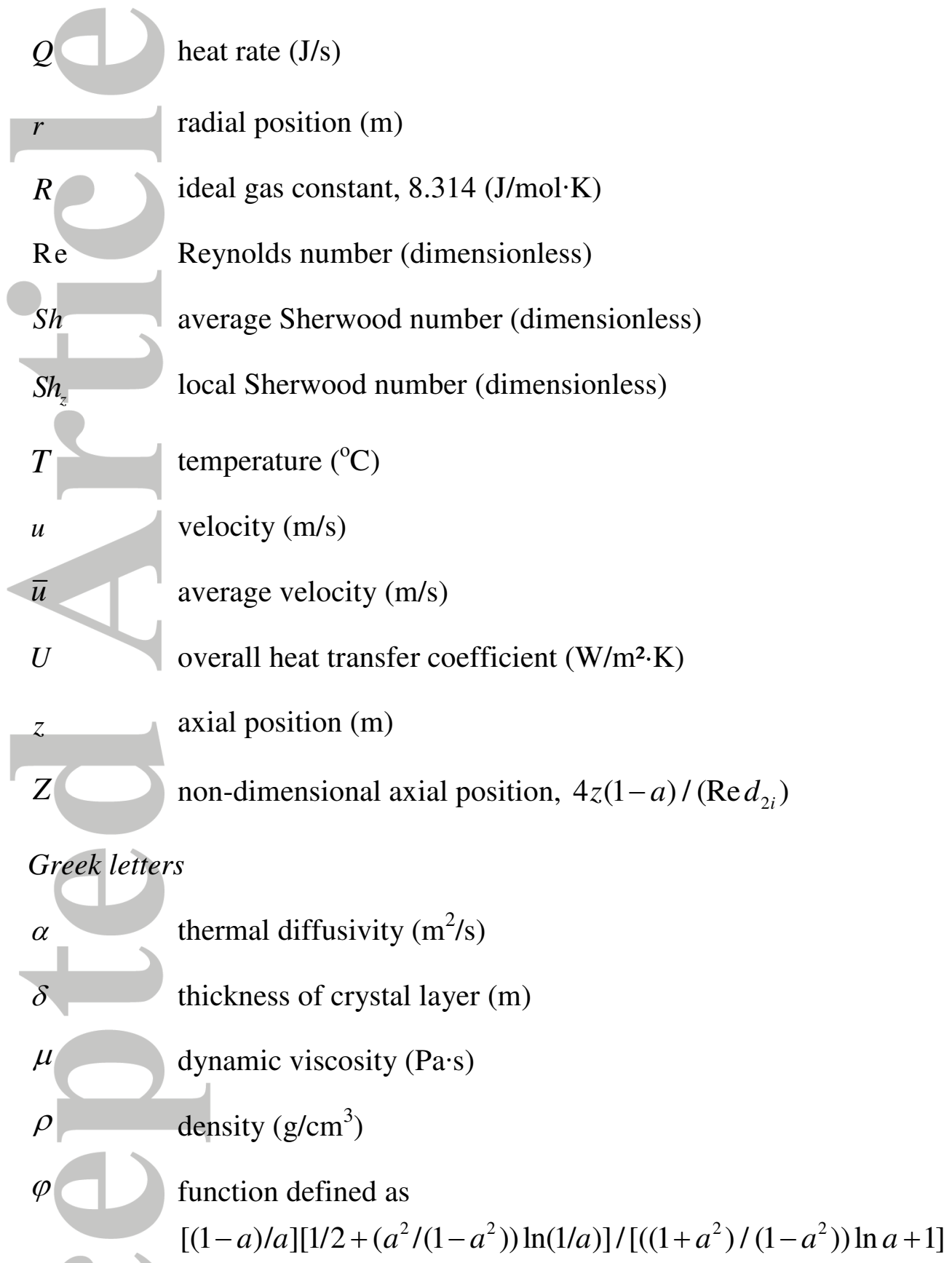




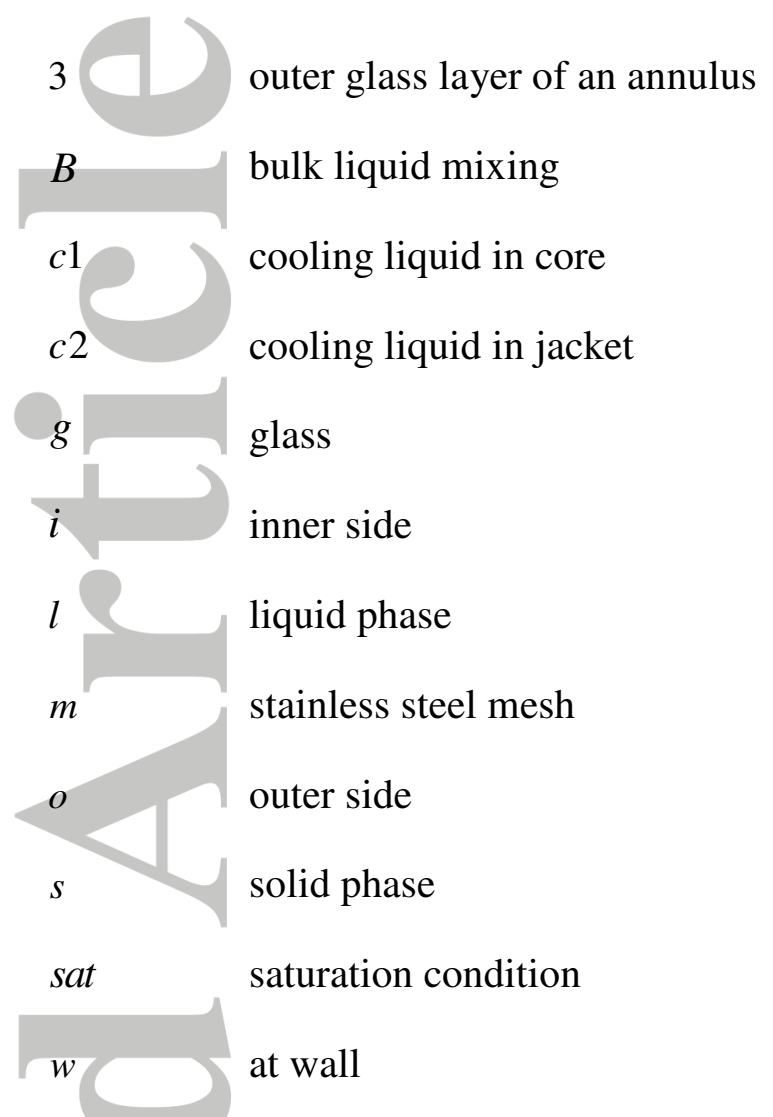

\section{Literature Cited}

1. Beck R, Häkkinen A, Malthe-Sørenssen D, Andreassen J-P. The effect of crystallization conditions, crystal morphology and size on pressure filtration of L-glutamic acid and an aromatic amine. Sep. Purif. Technol. 2009;66(3):549-558.

2. Glade H, Ulrich J. Melt Crystallization: Fundamentals, Equipment and Applications: Shaker; 2003.

3. Ulrich J, Bülau HC. 7 - Melt crystallization. In: Myerson AS, ed. Handbook of Industrial Crystallization. 2nd ed. Woburn: Butterworth-Heinemann; 2002:161-179.

4. Parisi M, Chianese A. The crystal layer growth from a well-mixed melt. Chemical Engineering Science. 2001;56(14):4245-4256.

5. Rich A, Mandri Y, Mangin D, et al. Sea water desalination by dynamic layer melt crystallization: Parametric study of the freezing and sweating steps. Journal of Crystal Growth. 2012;342(1):110-116.

6. Flesland O. Freeze concentration by layer crystallization. Drying Technol. 1995;13(89):1713-1739.

7. Peters-Erjawetz S, Ulrich J, Tiedtke M, Hartel R. Milk fat fractionation by solid-layer melt crystallization. Journal of the American Oil Chemists' Society. 1999;76(5):579-584.

8. Guardani R, Neiro SMS, Bülau H, Ulrich J. Experimental comparison and simulation of static and dynamic solid layer melt crystallization. Chemical Engineering Science. 2001;56(7):2371-2379.

9. Fukui K, Maeda K. Direct numerical simulation of solid-layer crystallization from binary melt. Journal of Crystal Growth. 2002;235(1-4):633-639. 
10. Dai W, Feng Z, Nassar R, Palmer J. A combined analytic and numerical method for predicting the solid-layer growth from melt crystallization. Numerical Heat Transfer, Part A: Applications. 2003;44(6):577-590.

11. Ossipov P. Optimization of heat-mass transfer at continuous solid layer crystallization on a belt. Applied Mathematical Modelling. 1999;23(5):419-436.

12. Wallert C, Marquardt W, Leu JT, Strube J. Design and optimization of layer crystallization processes. In: Luis P, Antonio E, eds. Computer Aided Chemical Engineering. Vol 20: Elsevier; 2005:871-876.

13. Aumock NM. A Process for Separation by Semi-Continuous Counter-Current Crystallization. Cambridge, MA: Dept. of Chemical Engineering, Massachusetts Institute of Technology; 2011.

14. Rai BN, Sinha AK, Ghosh UK, Gupta SN, Upadhyay SN. Forced convective mass transfer in annuli. Chemical Engineering Communications. 1988;68(1):15-30.

15. Turitto VT. Mass transfer in annuli under conditions of laminar flow. Chemical Engineering Science. 1975;30(5-6):503-509.

16. Houzelot J-L, Villermaux J. Mass transfer in annular cylindrical reactors in laminar flow. Chemical Engineering Science. 1977;32(12):1465-1470.

17. Ross TK, Wragg AA. Electrochemical mass transfer studies in annuli. Electrochim. Acta. 1965;10(11):1093-1106.

18. Mobarak AA, Farag HA, H.Sedahmed G. Mass transfer in smooth and rough annular ducts under developing flow conditions. J. Appl. Electrochem. 1997;27(2):201-207.

19. Ould-Rouis M, Salem A, Legrand J, Nouar C. Etude numérique et expérimentale des transferts de matière et de quantité de mouvement dans un écoulement annulaire laminaire non établi. Int. J. Heat Mass Transfer. 1995;38(6):953-967.

20. Ghosh UK, Upadhyay SN. Mass transfer to newtonian and non-newtonian fluids in short annuli. AIChE Journal. 1985;31(10):1721-1724.

21. Guardani R, Belline A. Application of mathematical modelling in a two-component layer crystallisation process. Chemical Engineering \& Technology. 1997;20(7):495-501.

22. Esteban Duran J, Taghipour F, Mohseni M. CFD modeling of mass transfer in annular reactors. Int. J. Heat Mass Transfer. 2009;52(23-24):5390-5401.

23. Dirker J, Meyer JP. Heat transfer coefficients in concentric annuli. J. Heat Transfer. 2002;124(6):1200-1203.

24. Dirker J, Meyer JP. Convective heat transfer coefficients in concentric annuli. Heat Transfer Engineering. 2005;26(2):38-44.

25. Batra RL, Sudarsan VR. Laminar flow heat transfer in the entrance region of concentric annuli for power law fluids. Computer Methods in Applied Mechanics and Engineering. 1992;95(1):1-16.

26. Hatton AP, Quarmby A. Heat transfer in the thermal entry length with laminar flow in an annulus. Int. J. Heat Mass Transfer. 1962;5(10):973-980.

27. Malon A, Muller T. A short method to compute Nusselt numbers in rectangular and annular channels with any ratio of constant heat rate. Journal of Engineering for Gas Turbines and Power. 2012;134(3):032902.

28. Viskanta R. Heat transfer with laminar flow in a concentric annulus with prescribed wall temperatures. Appl. Sci. Res. 1964;12(6):463-476.

29. Mitrović J, Maletić B. Effect of thermal asymmetry on heat transfer in a laminar annular flow. Chemical Engineering \& Technology. 2005;28(10):1144-1150. 
30. Kirkpatrick JP, McIntire LV, Characklis WG. Mass and heat transfer in a circular tube with biofouling. Water Res. 1980;14(2):117-127.

31. Al-Darbi MM, Agha KQ, Islam MR. Estimation of the substrate concentration profiles in petroleum pipelines containing biofilms. Pet. Sci. Technol. 2006;24(11):1249-1265.

32. Chianese A, Santilli N. Modelling of the solid layer growth from melt crystallizationthe integral formulation approach. Chemical Engineering Science. 1998;53(1):107-111.

33. Bird RB, Stewart WE, Lightfoot EN. Transport Phenomena. 2nd ed: John Wiley \& Sons; 2007.

34. Quon JL, Zhang H, Alvarez A, Evans J, Myerson AS, Trout BL. Continuous crystallization of Aliskiren hemifumarate. Crystal Growth \& Design. 2012.

35. Nývlt J. Nucleation and growth rate in mass crystallization. Progress in Crystal Growth and Characterization. 1984;9(3-4):335-370.

36. Wilke CR, Chang P. Correlation of diffusion coefficients in dilute solutions. AIChE Journal. 1955;1(2):264-270.

37. Lin Y, Shi Z, Wildfong PLD. Thermal conductivity measurements for small molecule organic solid materials using modulated differential scanning calorimetry (MDSC) and data corrections for sample porosity. J. Pharm. Biomed. Anal. 2010;51(4):979-984.

38. Glicksman M, Schaefer R, Ayers J. Dendritic growth-A test of theory. Metallurgical and Materials Transactions A. 1976;7(11):1747-1759.

39. Brown RA. Theory of transport processes in single crystal growth from the melt. AIChE Journal. 1988;34(6):881-911.

40. Bergman TL, Lavine AS, Incropera FP, DeWitt DP. Fundamentals of Heat and Mass Transfer: John Wiley \& Sons; 2011.

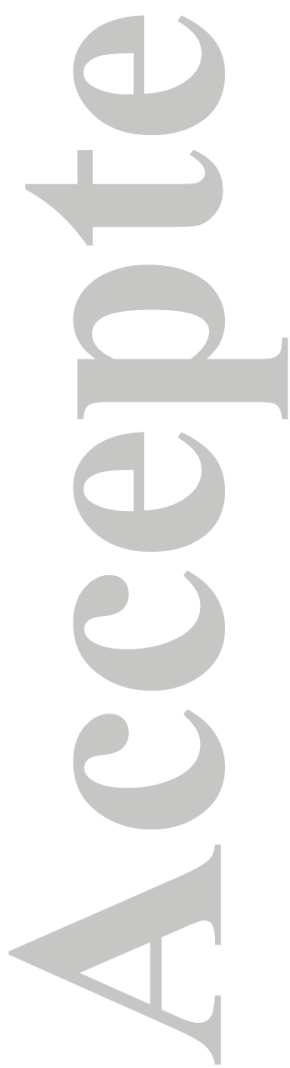


Table 1. Average Sherwood number in annuli with laminar flow

\begin{tabular}{lcccc}
\hline $\begin{array}{l}\text { Hydrodynamic } \\
\text { condition }\end{array}$ & Source & \multicolumn{1}{c}{ Correlation } & $\begin{array}{c}\text { Condition } \\
\#\end{array}$ & $\begin{array}{c}\text { Equation } \\
\text { Fully } \\
\text { developed }\end{array}$ \\
$\begin{array}{l}\text { Developing } \\
\text { Developing }\end{array}$ & 17 & $\mathrm{Sh}=1.614\left(\operatorname{ReSc} \varphi d_{e} / L\right)^{1 / 3}$ & \\
& 19 & $\mathrm{Sh}=1.029 \mathrm{Sc}^{1 / 3} \operatorname{Re}^{0.55}\left(d_{e} / L\right)^{0.472}$ & & $(43)$ \\
Developing & 20 & $\mathrm{Sh}=0.66 \mathrm{Sc}^{1 / 3}\left(\operatorname{Re} \varphi d_{e} / L\right)^{0.52}$ & $Z \leq 42 \times 10^{-4}$ \\
\hline
\end{tabular}




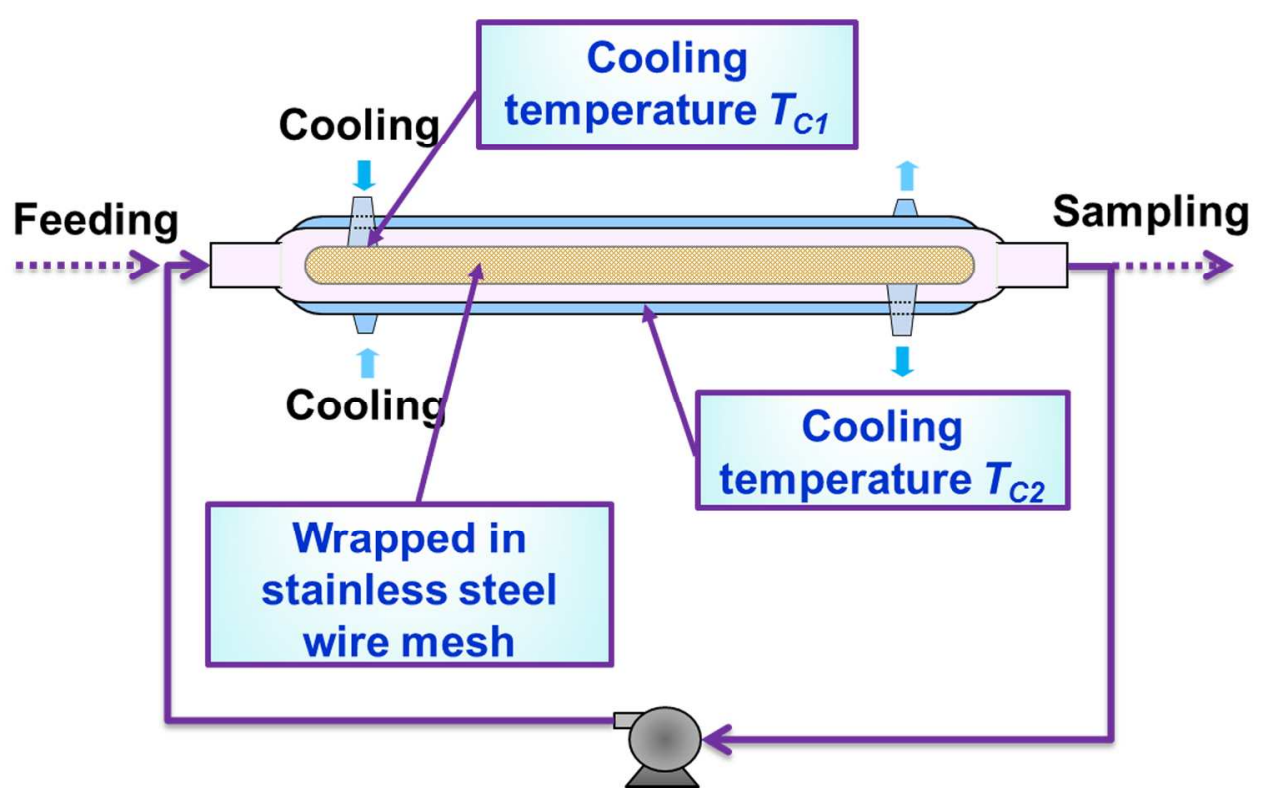

Figure 1. Schematic process flow diagram of the layer crystallization system. A recirculation loop can be used, as shown, to reduce mass transfer limitations so as to increase the crystal growth rate. $191 \times 113 \mathrm{~mm}(300 \times 300 \mathrm{DPI})$ 


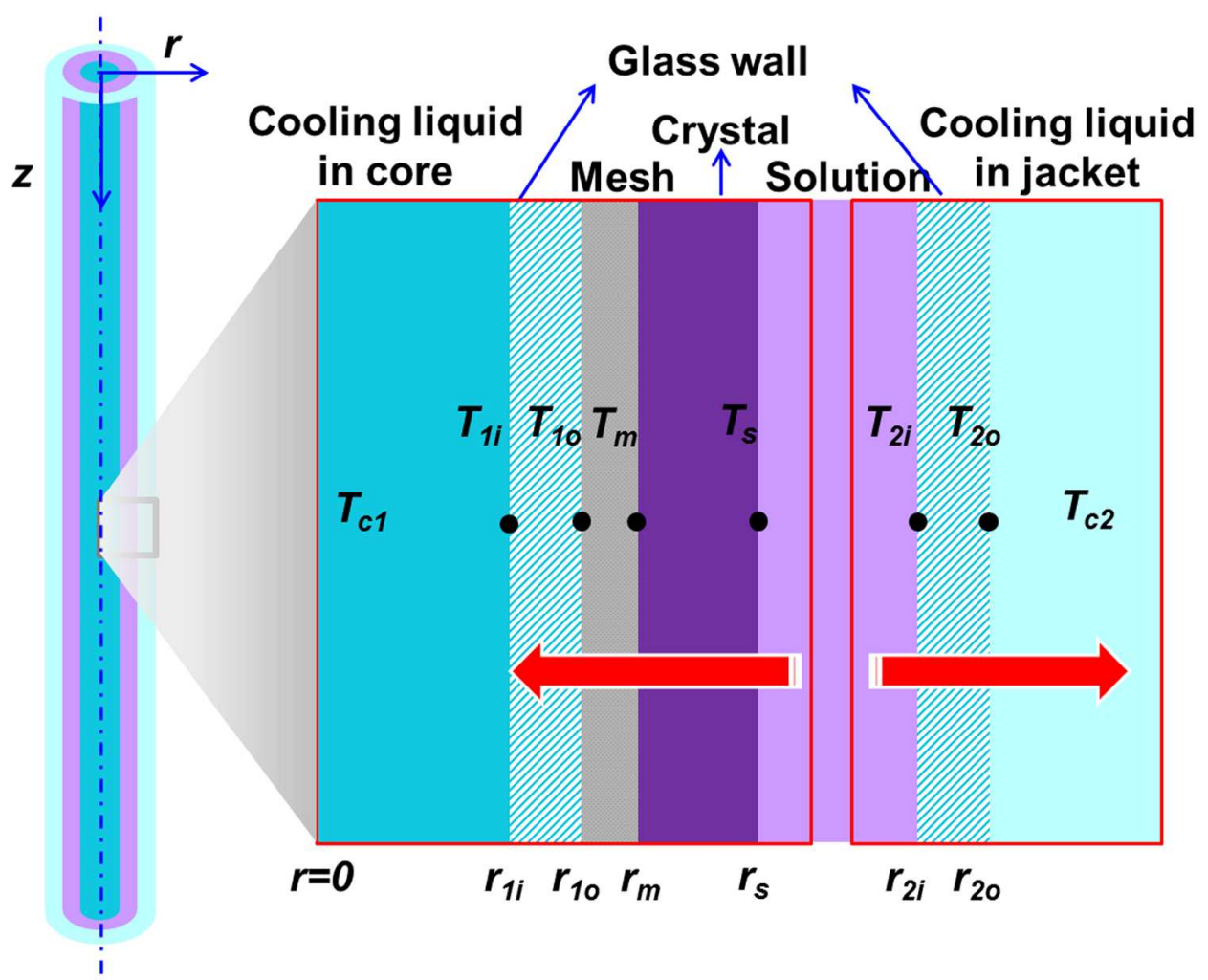

Figure 2. Schematic diagram of the annulus system with layer crystallization. Half of the system is shown with a mirror plane of symmetry at $r=0$. Red arrows show the direction of heat flux at the start of the crystal growth.

$191 \times 150 \mathrm{~mm}(300 \times 300$ DPI $)$ 


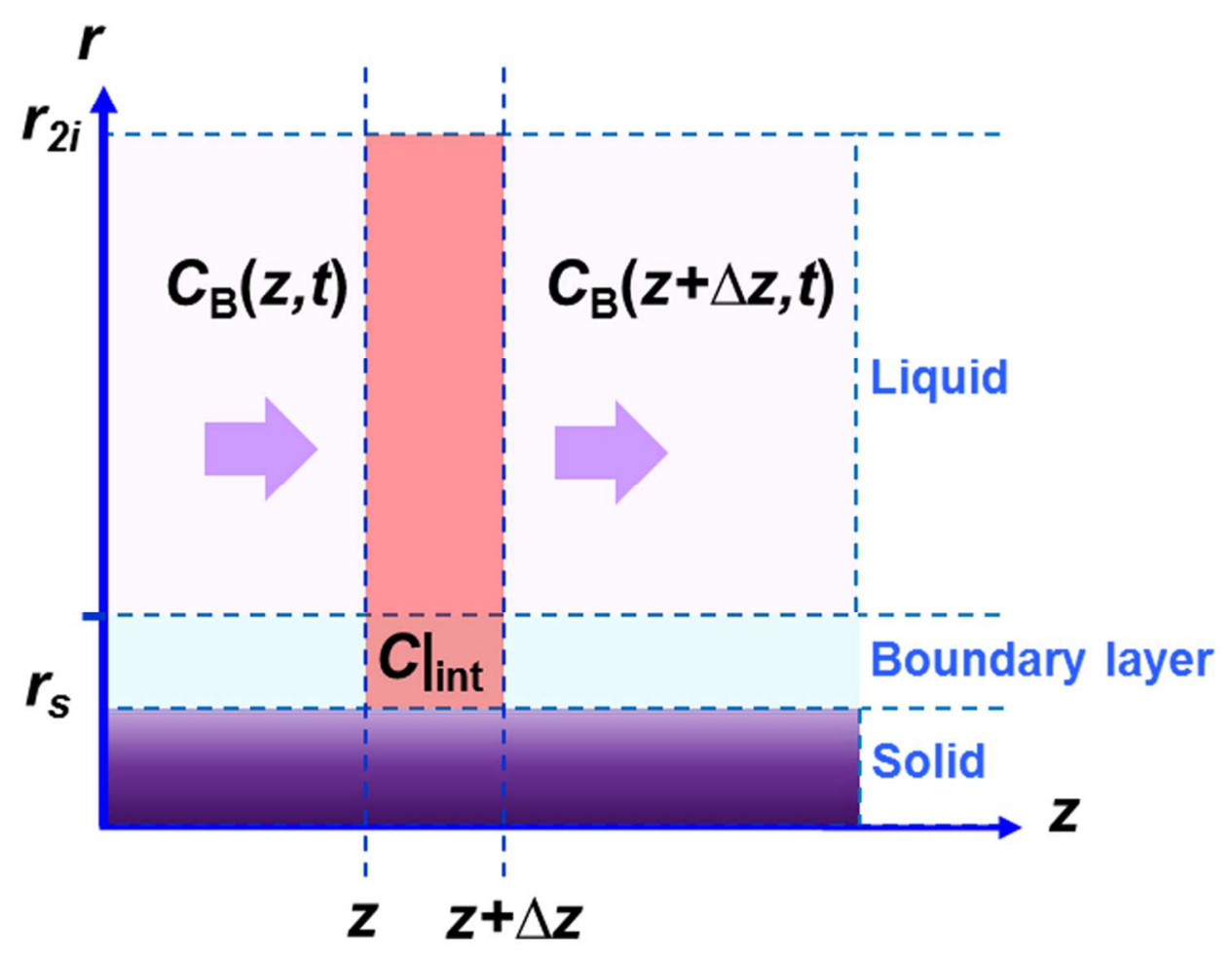

Figure 3. Solute mass balance in for a differential element in the axial direction. $113 \times 90 \mathrm{~mm}(300 \times 300 \mathrm{DPI})$ 


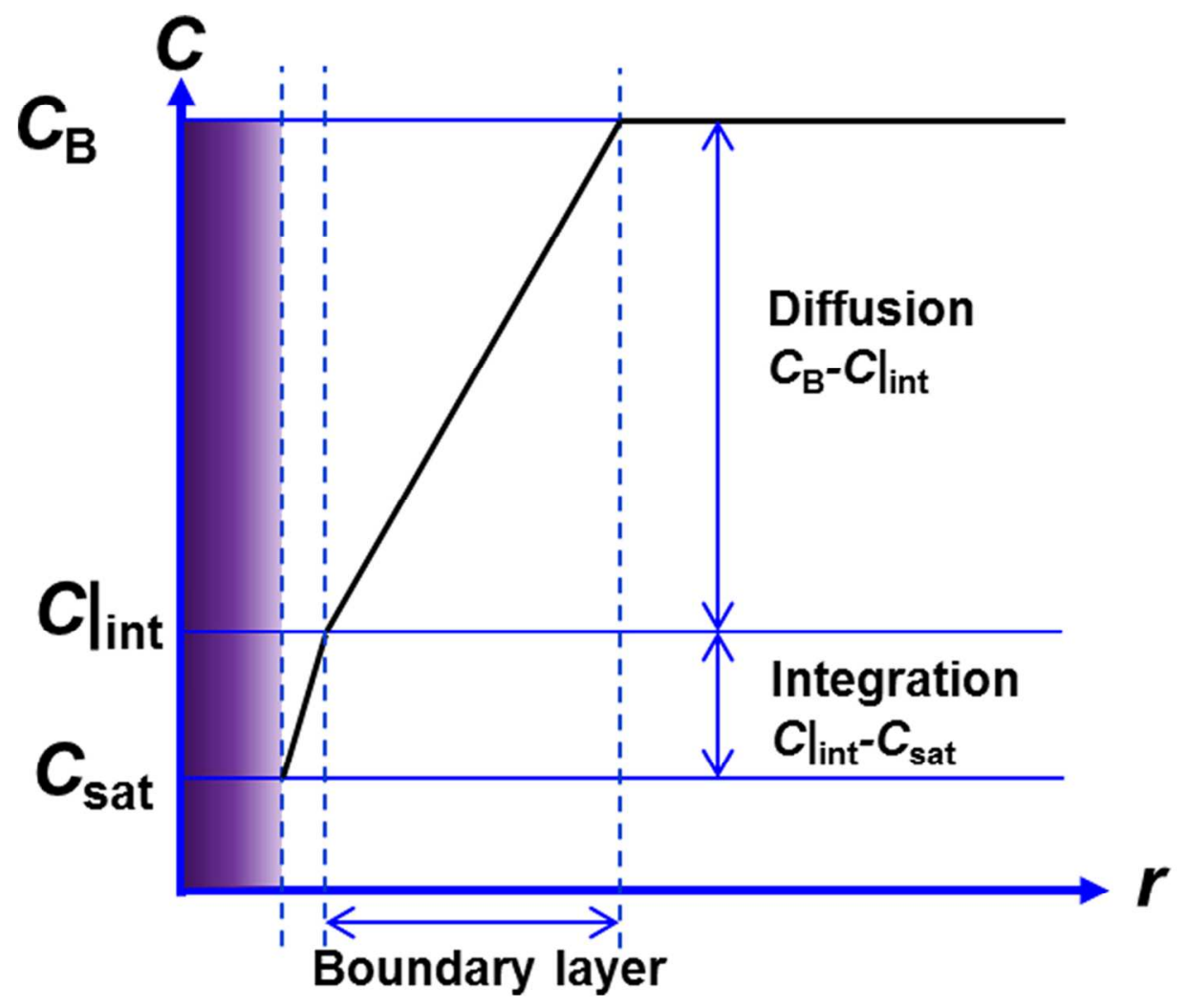

Figure 4. Diffusion layer growth model. ${ }^{34}$ $107 \times 91 \mathrm{~mm}(300 \times 300 \mathrm{DPI})$ 


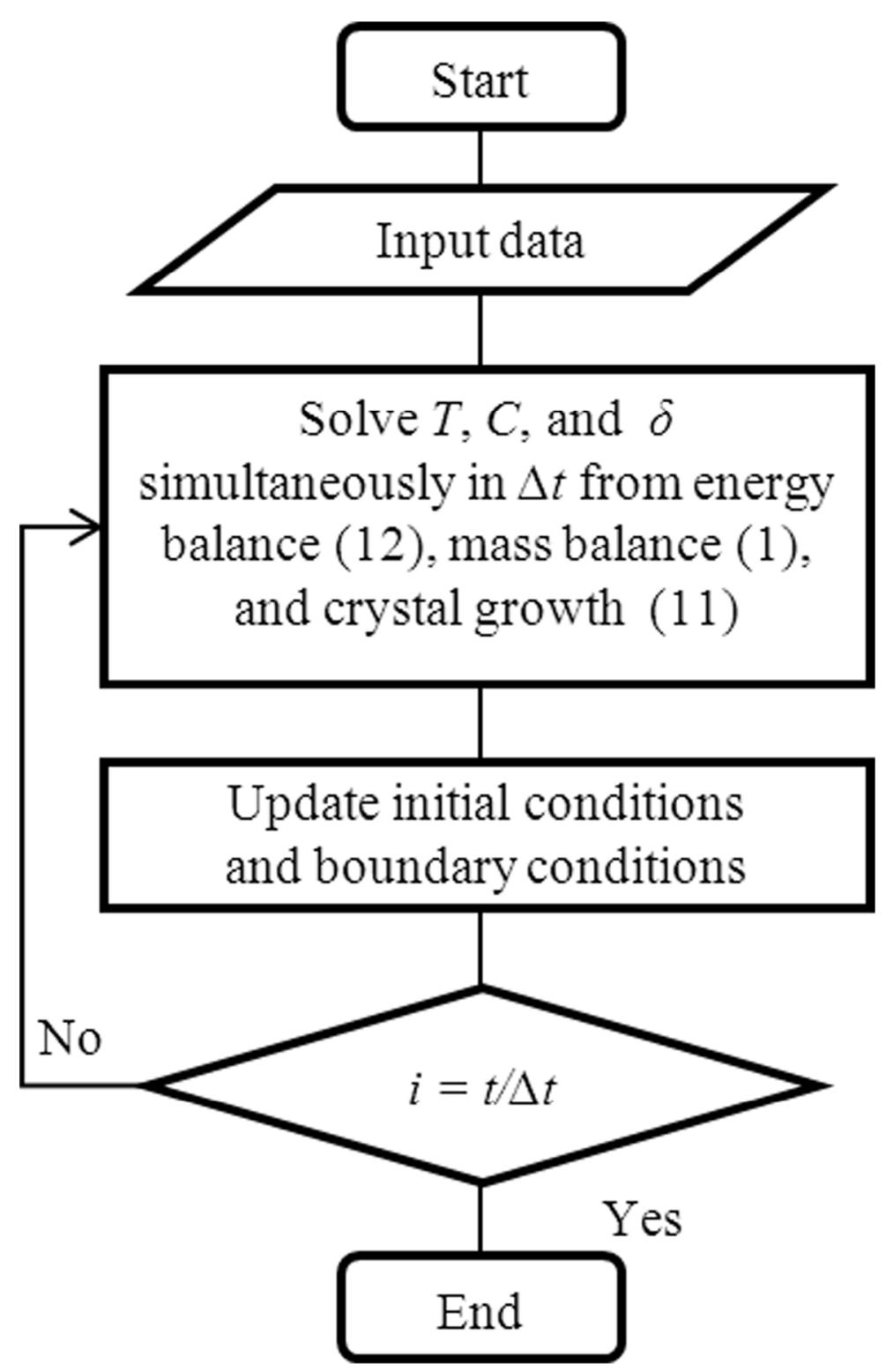

Figure 5. Numerical algorithm for solving the coupled partial differential equations for layer crystallization. $102 \times 142 \mathrm{~mm}(600 \times 600 \mathrm{DPI})$ 


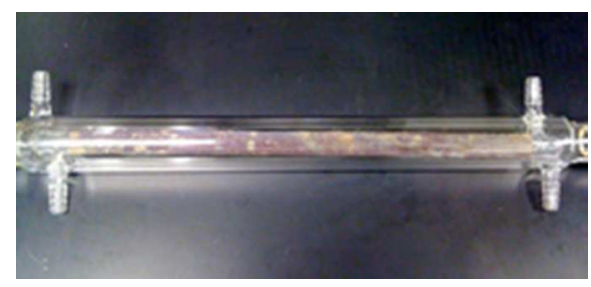

Figure 6. Layer crystallization apparatus used in the experiments. $18 \times 8 \mathrm{~mm}(300 \times 300 \mathrm{DPI})$ 


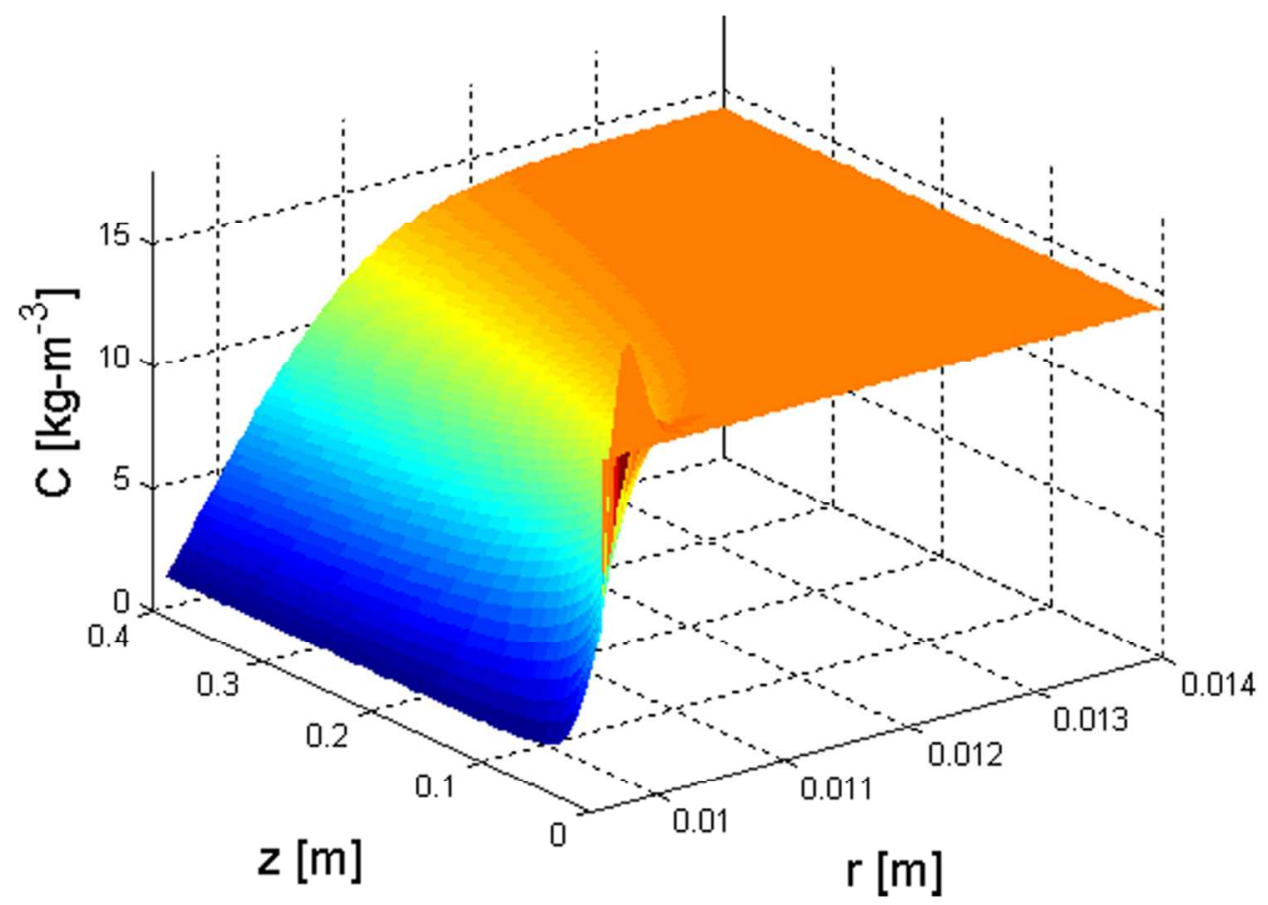

Figure 7. Solute concentration field. $80 \times 60 \mathrm{~mm}(300 \times 300 \mathrm{DPI})$ 


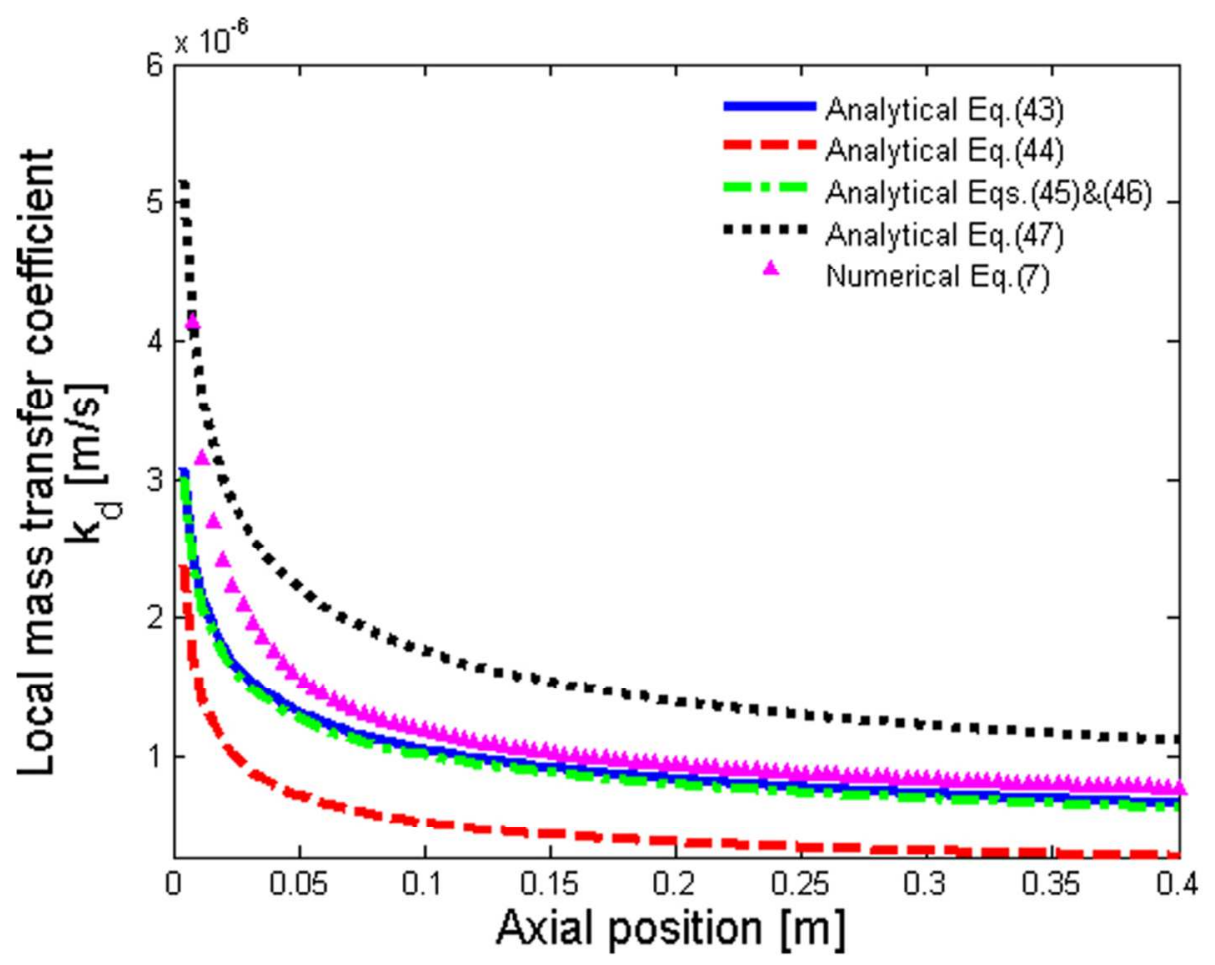

Figure 8. Numerical prediction of the local mass transfer coefficient vs. axial distance compared with values calculated from correlations.

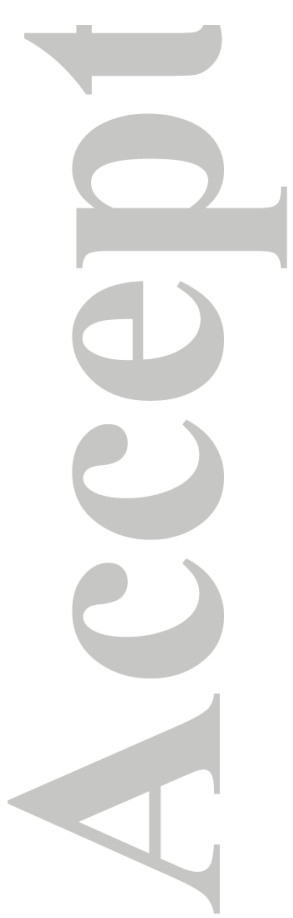

$80 \times 60 \mathrm{~mm}$ (300 x 300 DPI) 


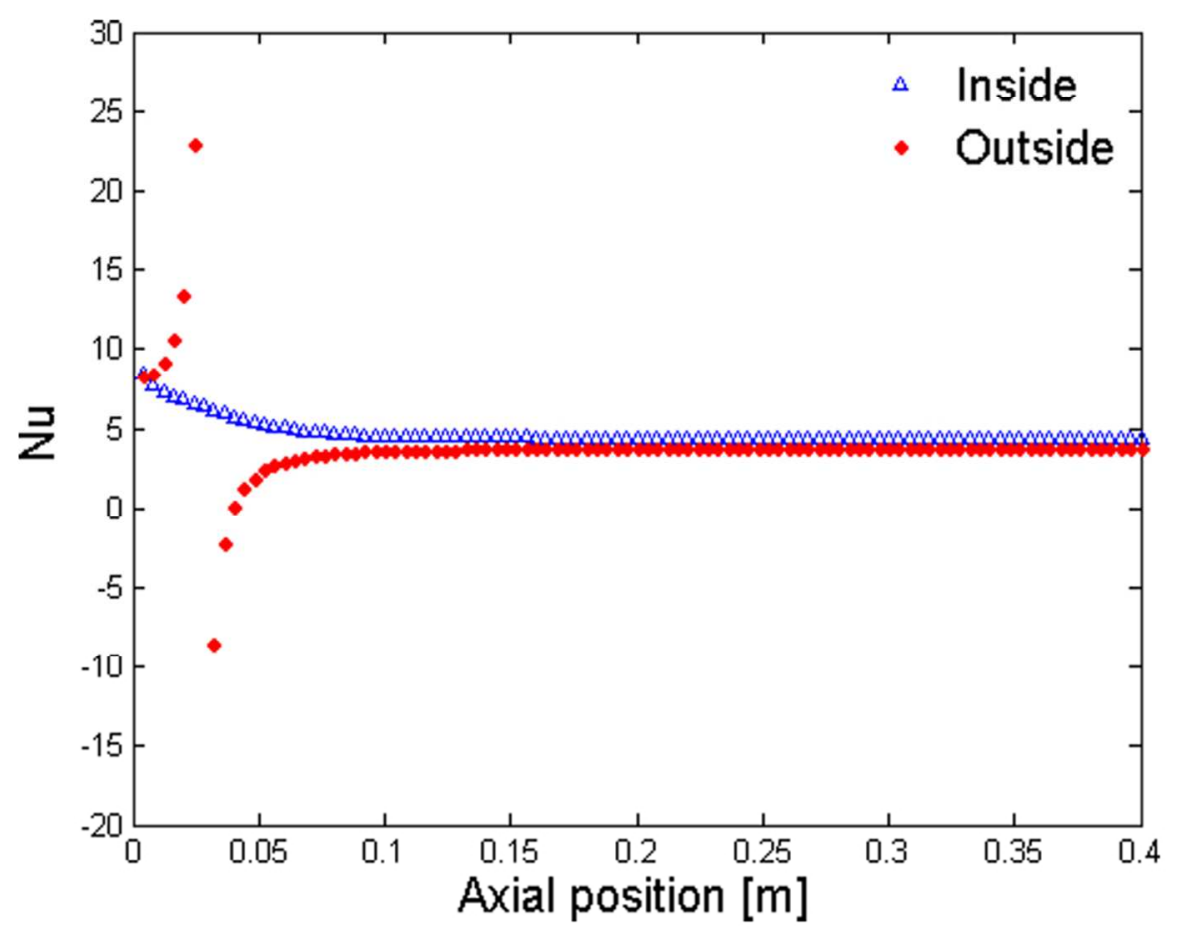

Figure 9. Nusselt numbers vs. axial distance. $80 \times 60 \mathrm{~mm}(300 \times 300$ DPI $)$ 


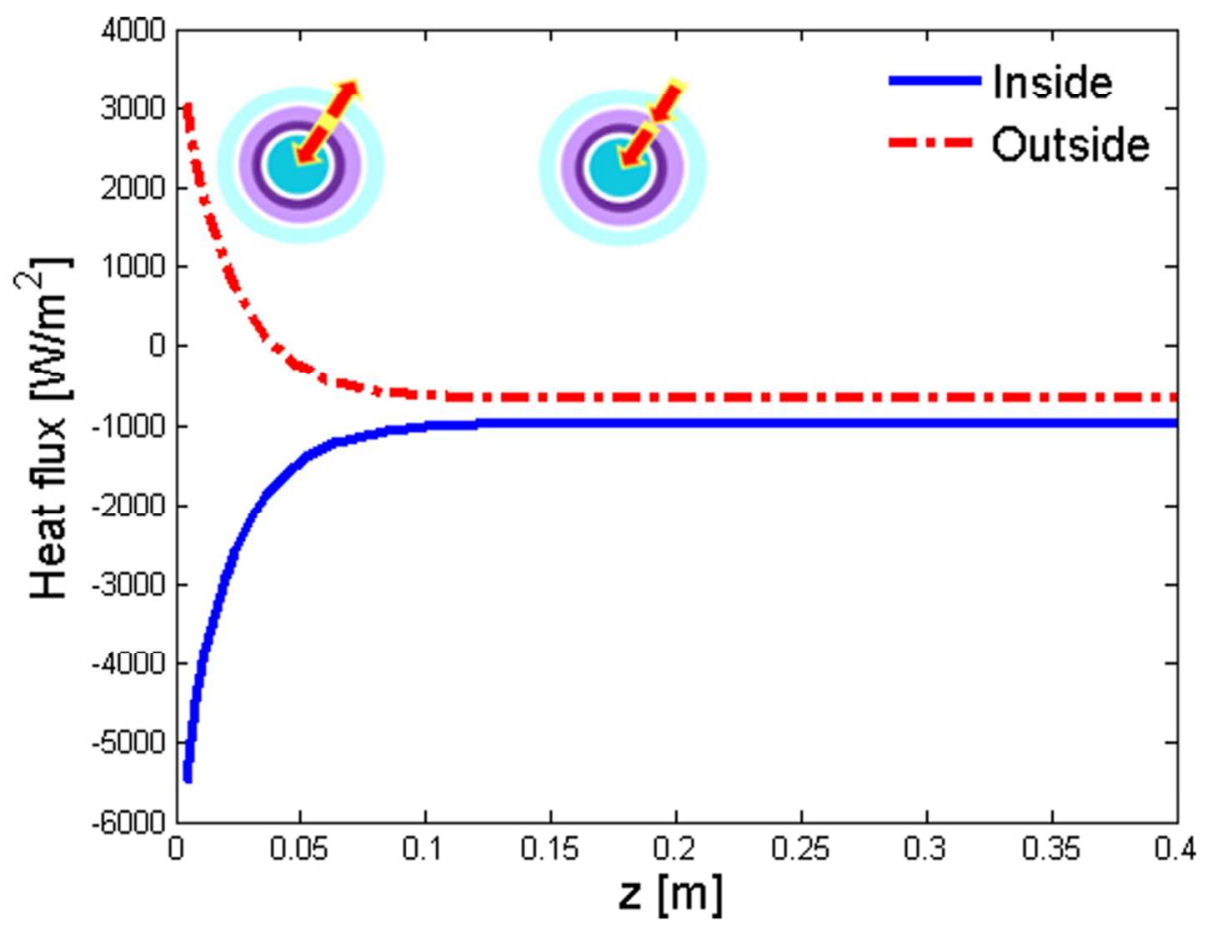

Figure 10. Heat flux vs. axial distance. $80 \times 60 \mathrm{~mm}(300 \times 300 \mathrm{DPI})$ 

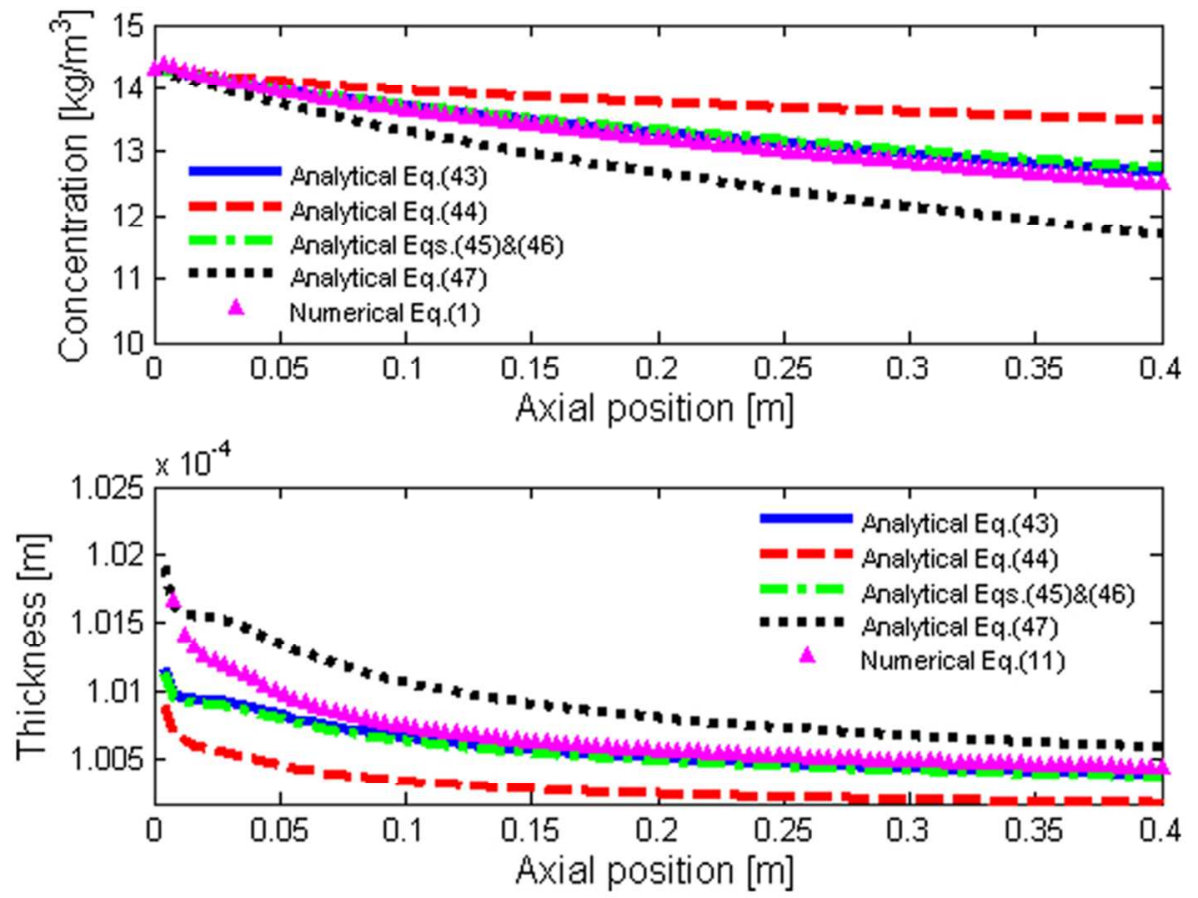

Figure 11. Numerical predictions of the concentration and crystal layer thickness vs. axial distance at time $t$ $=1 \mathrm{~min}$ are within the ranges given by analytical solutions calculated from correlations.

$80 \times 60 \mathrm{~mm}(300 \times 300$ DPI $)$ 


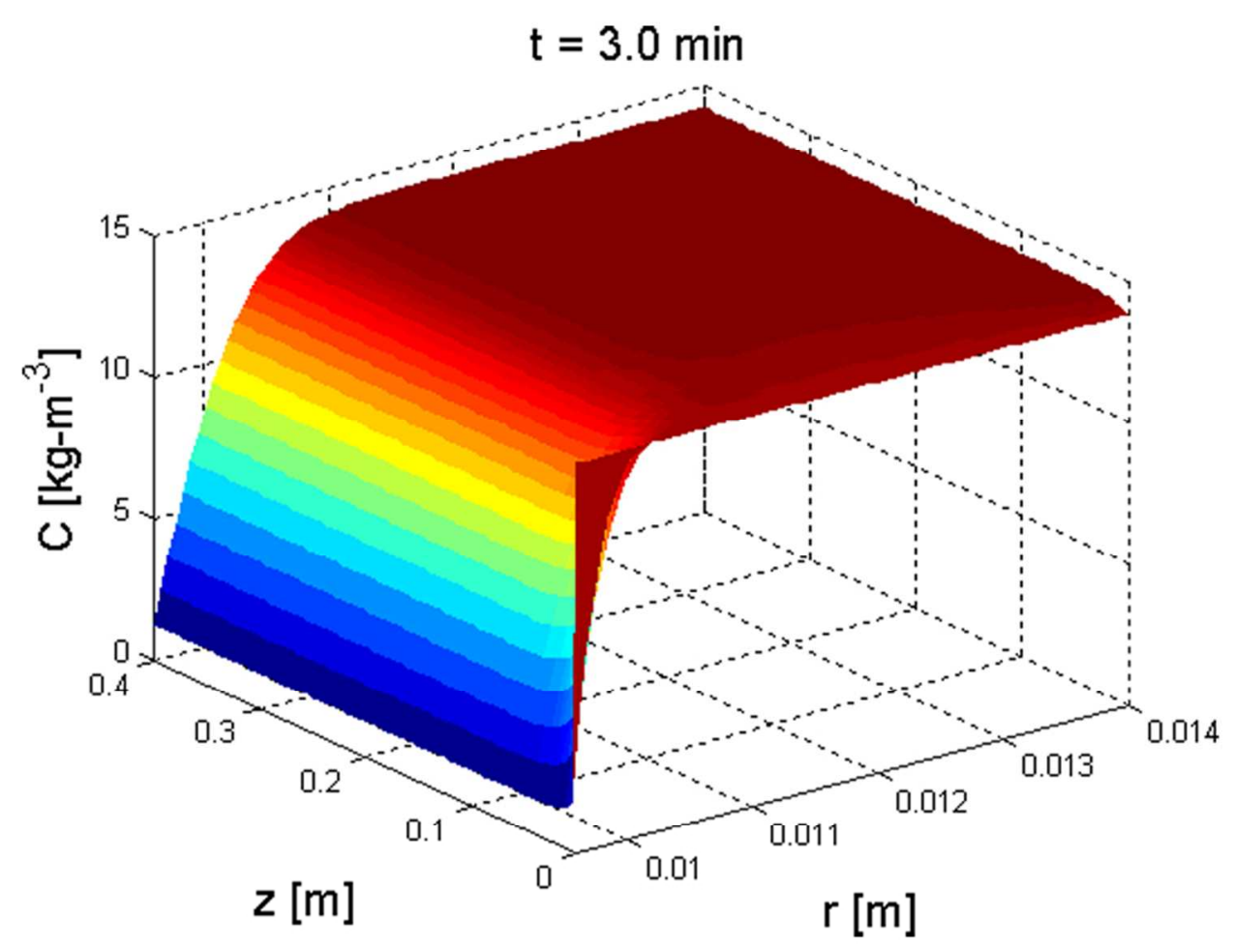

Figure 12. Solute concentration field at time $t=3 \mathrm{~min}$, with uniform mixing in the recirculation loop. $80 \times 60 \mathrm{~mm}(300 \times 300 \mathrm{DPI})$ 


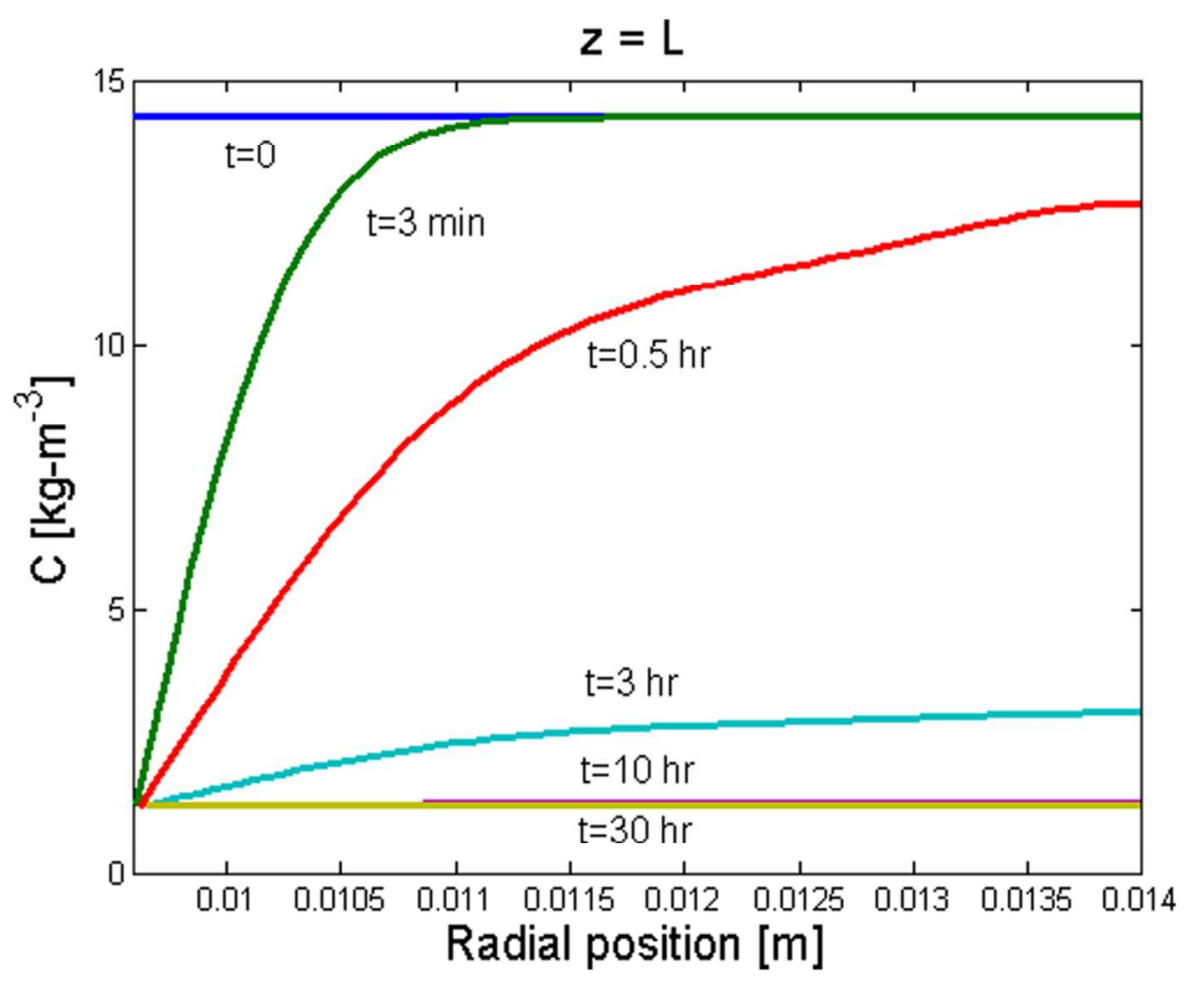

Figure 13. Dynamic radial exit concentration profiles, with uniform mixing in the recirculation loop. $80 \times 60 \mathrm{~mm}(300 \times 300 \mathrm{DPI})$

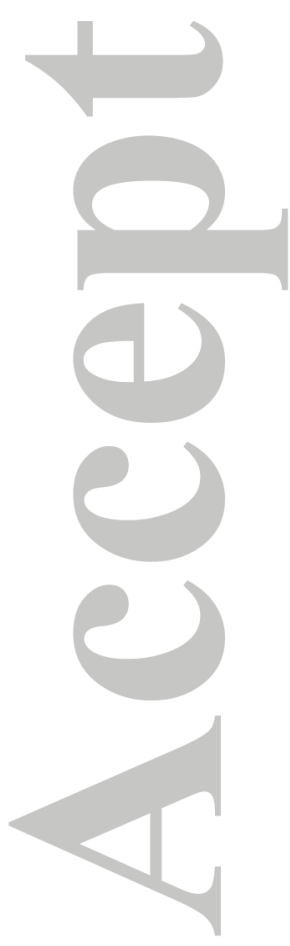




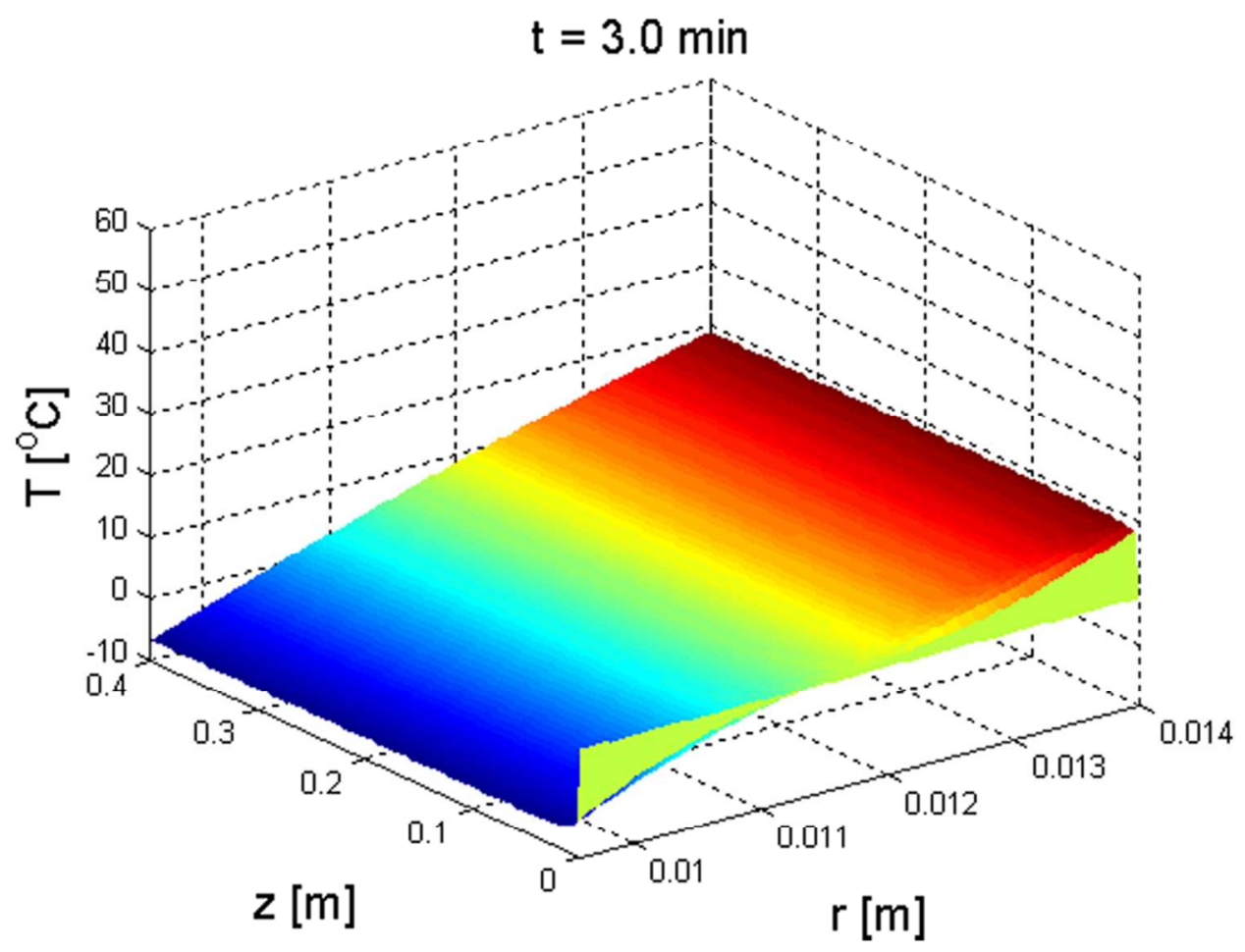

Figure 14. Temperature field at time $t=3 \mathrm{~min}$, with uniform mixing in the recirculation loop. $80 \times 60 \mathrm{~mm}(300 \times 300 \mathrm{DPI})$ 


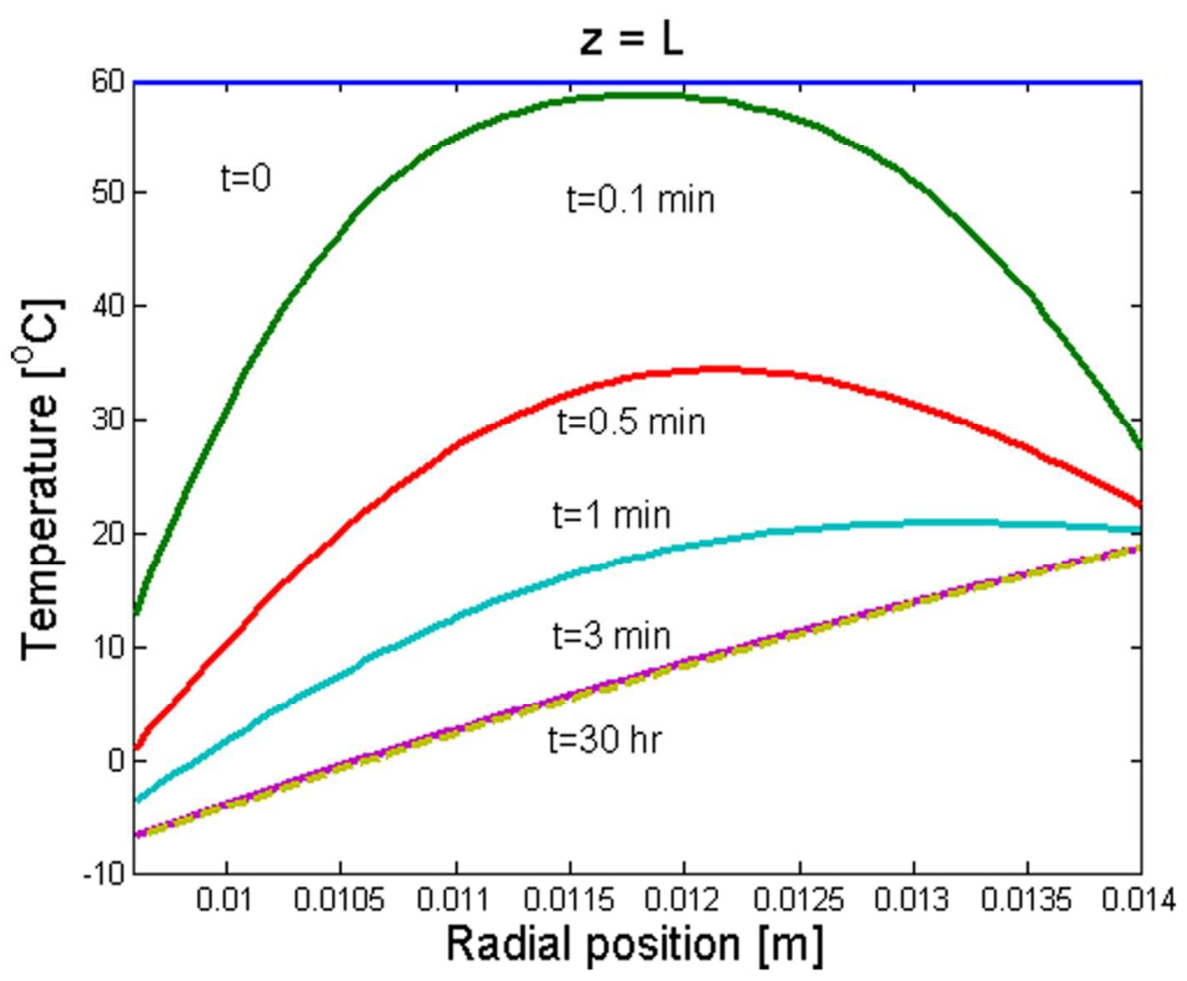

Figure 15. Dynamic radial exit temperature profiles, with uniform mixing in the recirculation loop. $80 \times 60 \mathrm{~mm}(300 \times 300 \mathrm{DPI})$ 


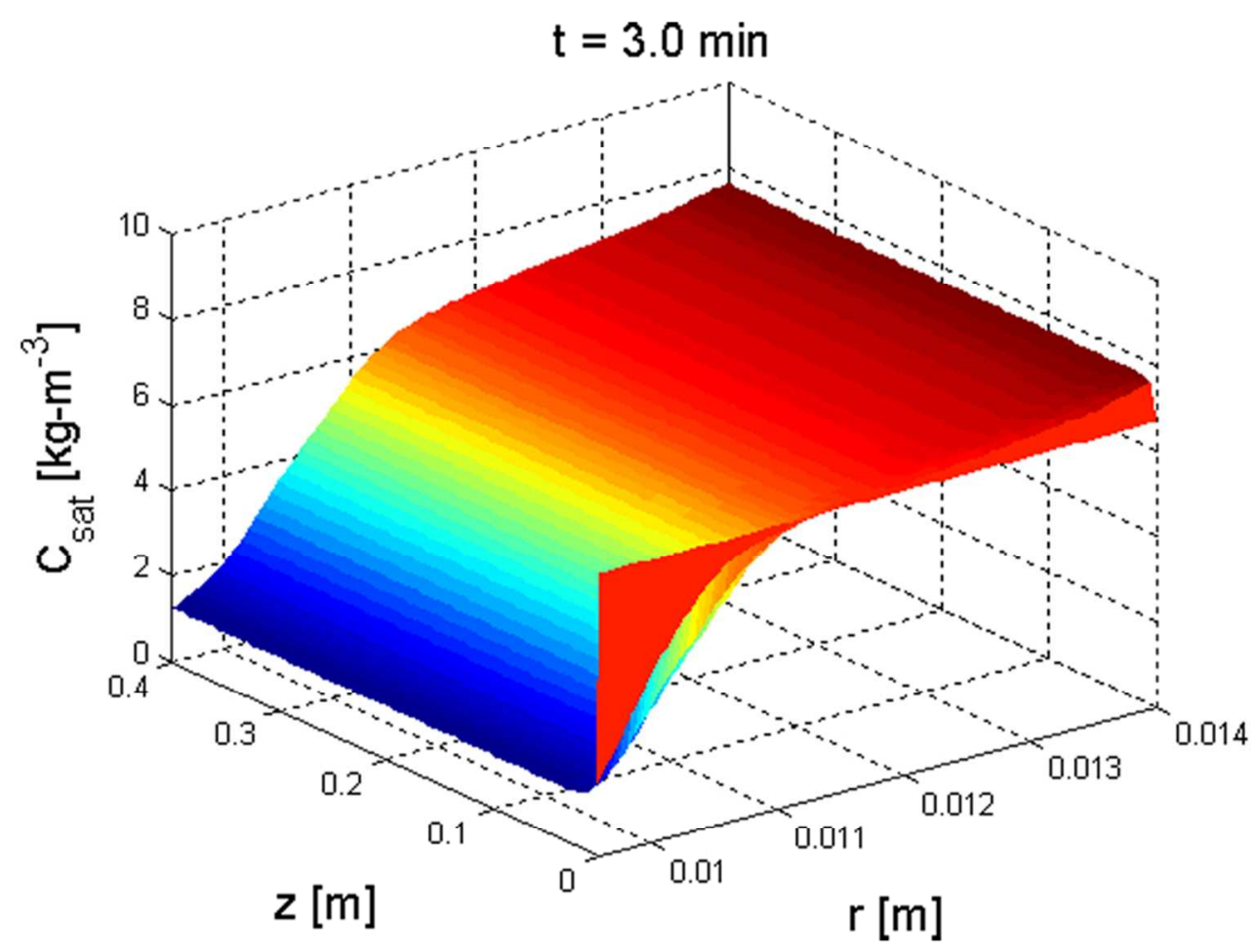

Figure 16. Saturated solute concentration field at $t=3 \mathrm{~min}$, with uniform mixing in the recirculation loop. $80 \times 60 \mathrm{~mm}(300 \times 300 \mathrm{DPI})$ 


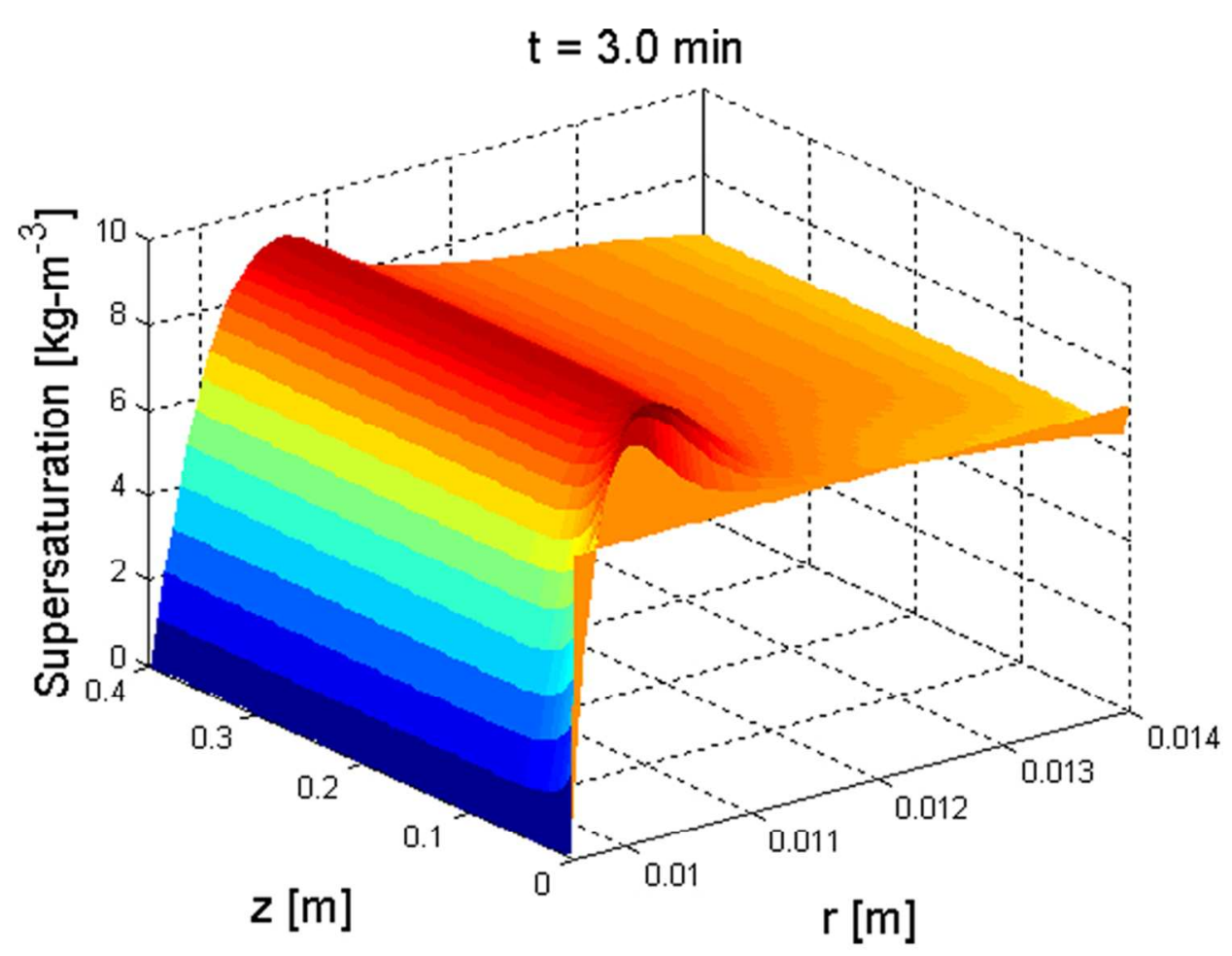

Figure 17. Absolute supersaturation field at $\mathrm{t}=3 \mathrm{~min}$, with uniform mixing in the recirculation loop. $80 \times 60 \mathrm{~mm}(300 \times 300 \mathrm{DPI})$ 


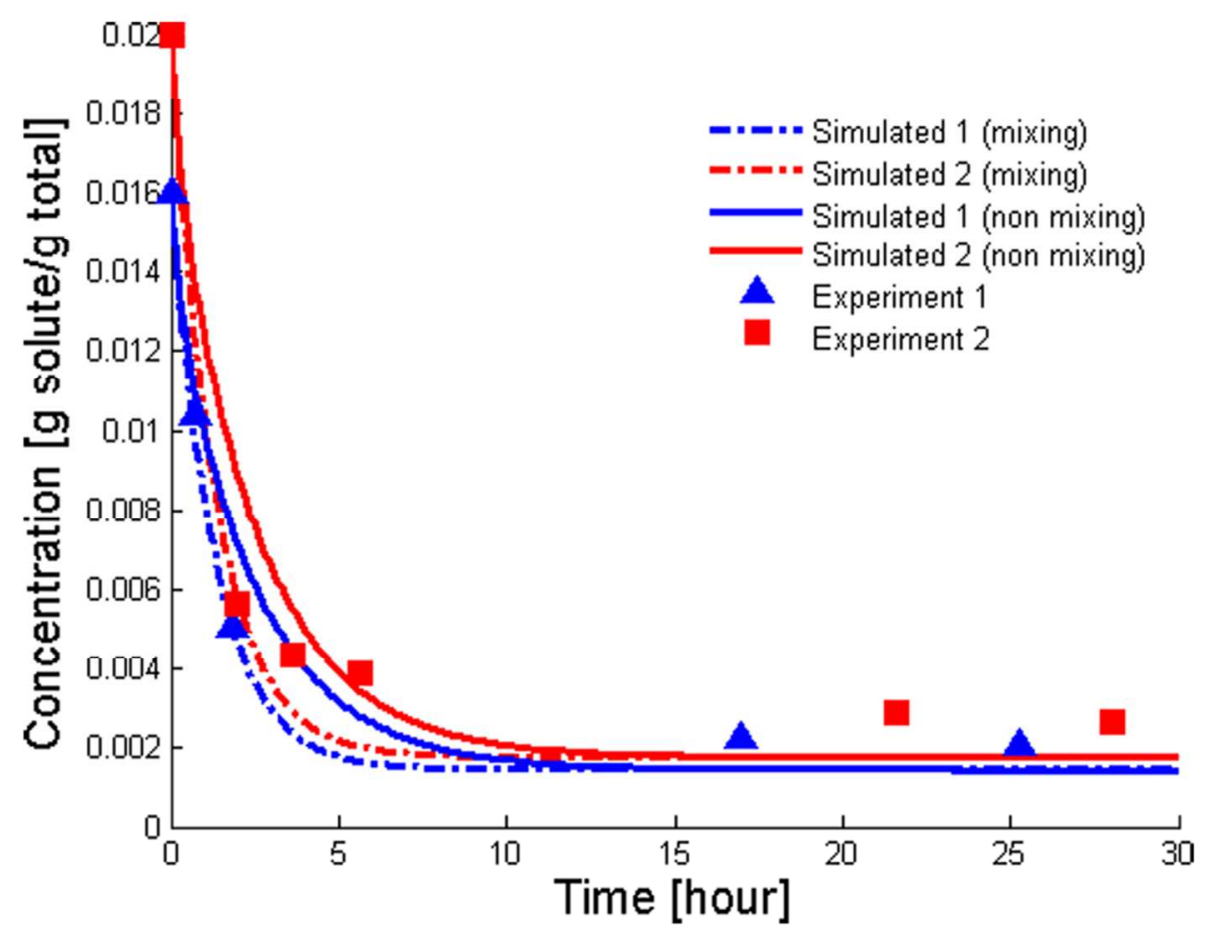

Figure 18. Comparison of the simulated exit concentrations for two different mixing conditions with experimental data vs. time for the total crystallization time of 30 hours. The conditions for Set 1 of simulations and experiments are $C_{0}=0.016 \mathrm{~g}$ solute $/ \mathrm{g}$ total and $T_{c 2}=20^{\circ} \mathrm{C}$ and Set 2 were $C_{0}=0.020 \mathrm{~g}$ solute $/ \mathrm{g}$ total and $T_{c 2}=30^{\circ} \mathrm{C}$. The other conditions are the same as described in the Experimental System and Parameters section.
$80 \times 60 \mathrm{~mm}(300 \times 300 \mathrm{DPI})$

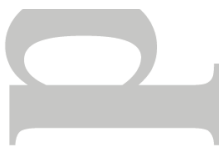




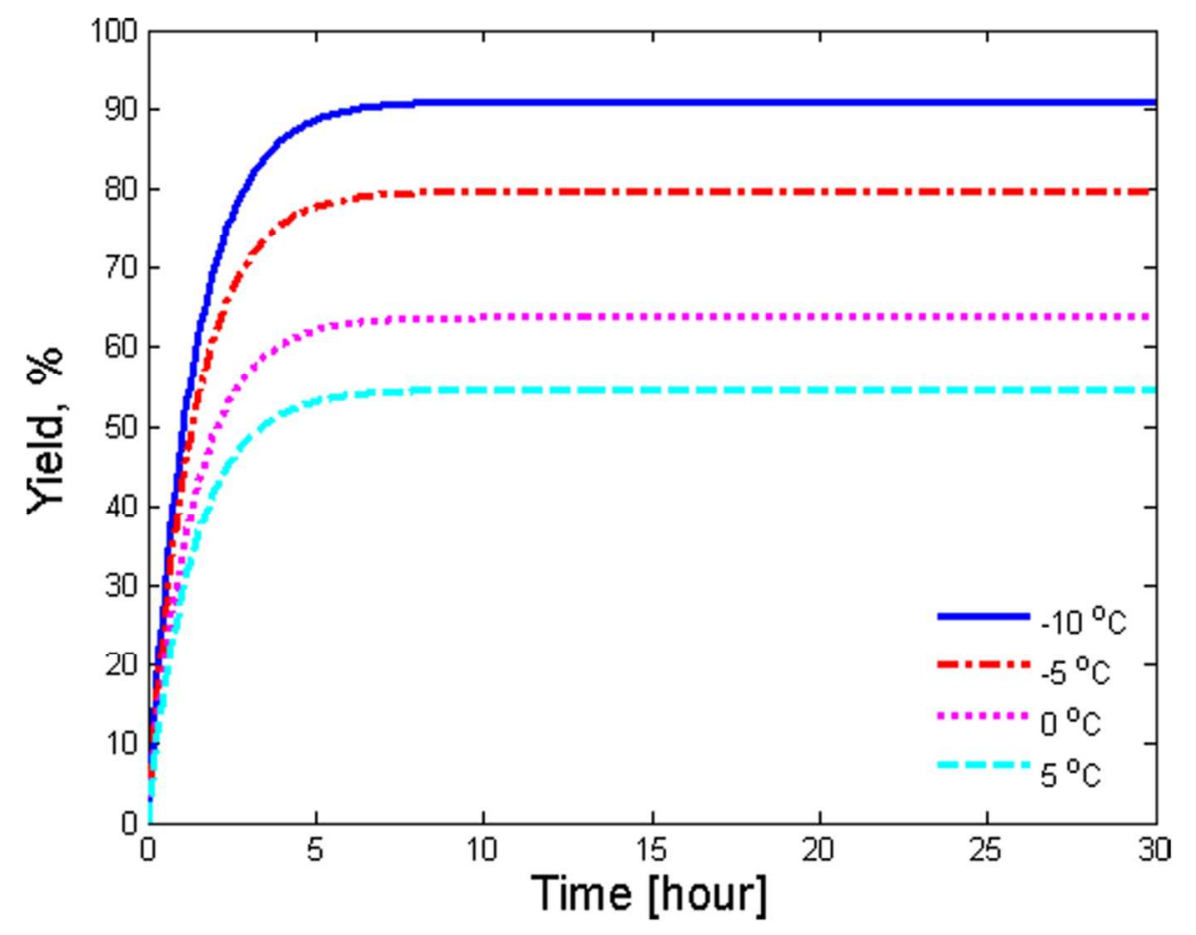

Figure 19. Model predictions for different values of $T_{c 1}$, with uniform mixing in the recirculation loop. $80 \times 60 \mathrm{~mm}(300 \times 300 \mathrm{DPI})$

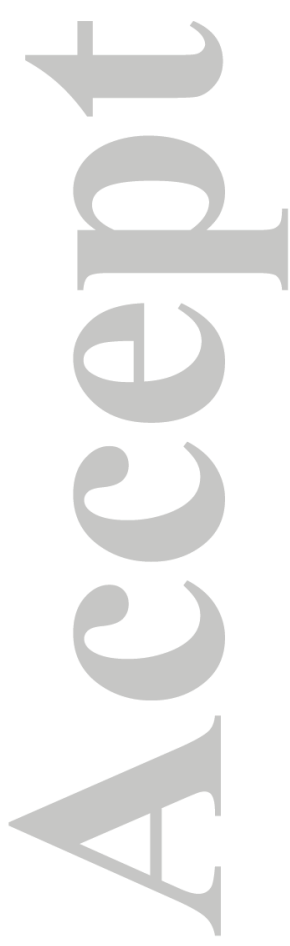



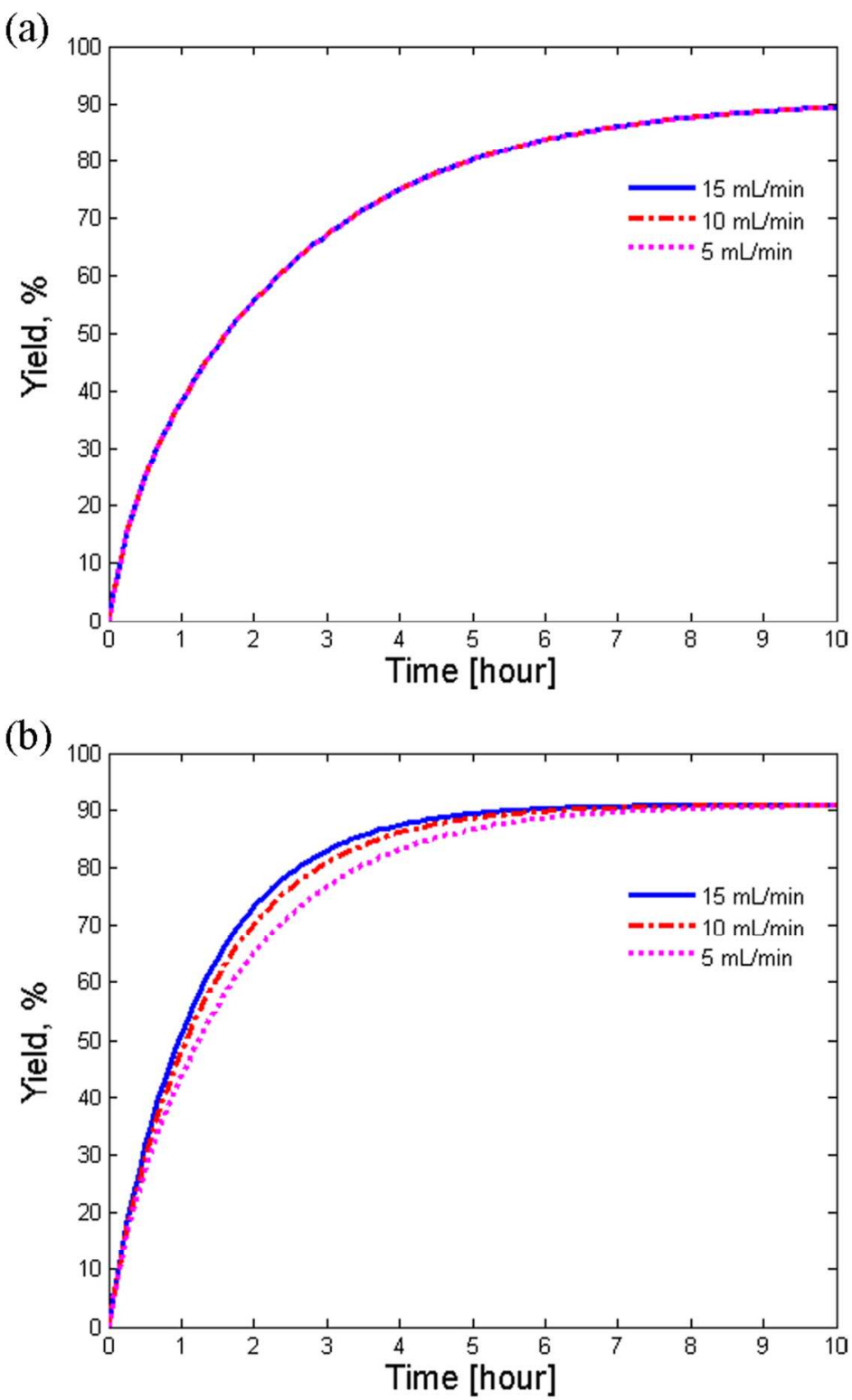

Figure 20. Temporal variation in the yield for different values of the solution flow rates. (a) no mixing in the recirculation loop and (b) uniform mixing in the recirculation loop. $80 \times 120 \mathrm{~mm}(300 \times 300$ DPI)

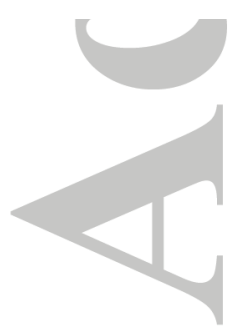



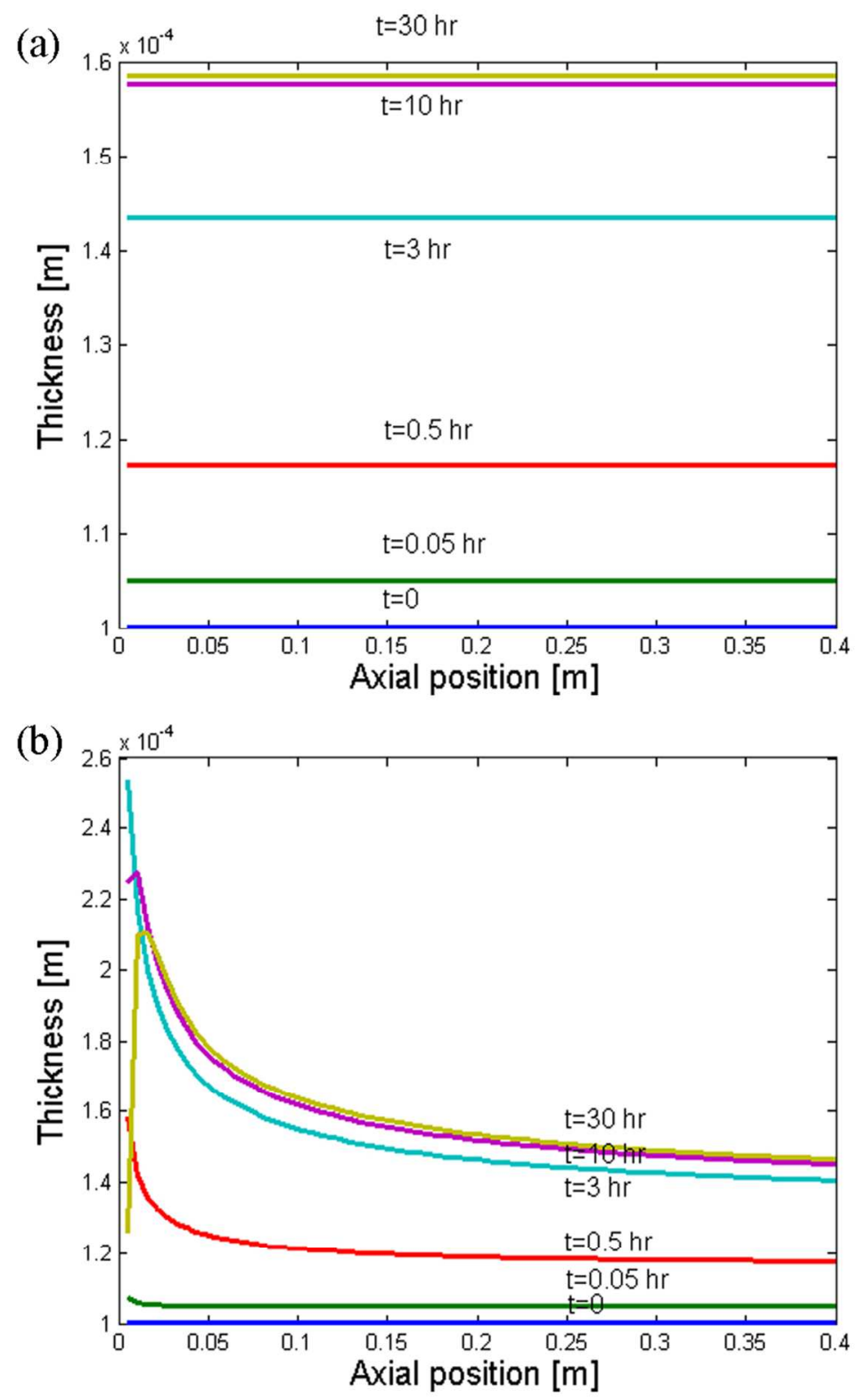

Figure 21. Temporal variation of the crystal layer thickness vs. axial position. (a) no mixing in the recirculation loop and (b) uniform mixing in the recirculation loop. $80 \times 120 \mathrm{~mm}(300 \times 300 \mathrm{DPI})$ 